\title{
Thinly traded securities and risk management ${ }^{\dagger}$
}

\section{Activos con baja frecuencia de transacciones y manejo de riesgo}

\author{
Alejandro Bernales* \\ DieTHER W. BEUERMANN** \\ GonZalo CORTAZAR ***
}

\begin{abstract}
Thinly traded securities exist in both emerging and well developed markets. However, plausible estimations of market risk measures for portfolios with infrequently traded securities have not been explored in the literature. We propose a methodology to calculate market risk measures based on the Kalman filter which can be used on incomplete datasets. We implement our approach in a fixed-income portfolio within a thin trading environment. However, a similar approach may be also applied to other markets with thinly traded securities. Our methodology provides reliable market risk measures in portfolios with infrequent trading.
\end{abstract}

Key words: Incomplete panels, Kalman filter, market risk, risk management, thin trading, value-at-risk.

JEL Classification: $G 11, G 12, G 32$.

\section{Resumen}

Los activos financieros con baja frecuencia de transacciones existen tanto en mercados emergentes como desarrollados. Sin embargo, no han sido exploradas en la literatura estimaciones robustas de medidas de riesgo de mercado para carteras compuestas por activos, los cuales no son transados frecuentemente. Proponemos una metodología para calcular medidas de riesgo de mercado

$\dagger$ The authors would like to thank the comments from two anonymous referees that substantially improved our study. Gonzalo Cortazar acknowledges partial financial support from Fondecyt (1130352) and from Grupo Security through FinanceUC.

* Banque de France and Universidad de Chile (Centro de Finanzas). Address: 31 Rue Croix des Petits Champs, 75001 Paris, France. E-mail: alejandro.bernales@banque-france.fr.

** Inter-American Development Bank. Address: 1300 New York Ave. NW, Washington, DC 20577. E-mail: dietherbe@iadb.org.

*** Pontificia Universidad Católica de Chile (Ingeniería Industrial y de Sistemas). Address: Vicuña Mackenna 4860, Santiago Chile. E-mail: gcortaza@ing.puc.cl. 
basada en el filtro de Kalman, el cual puede ser utilizado con paneles de datos incompletos. Asimismo, implementamos nuestra metodología en una cartera de instrumentos de renta fija dentro de un entorno con baja frecuencia de transacciones. No obstante, la metodología es también aplicable a otro tipo de mercados que sufran de baja frecuencia de transacciones. Nuestra metodología provee medidas robustas de riesgo de mercado en carteras con baja frecuencia de transacciones.

Palabras clave: Paneles incompletos, filtro de Kalman, riesgo de mercado, manejo de riesgo de mercado, baja frecuencia de transacciones, valor-en-riesgo.

Clasificación JEL: G11; G12; G32.

\section{INTRODUCTION}

One of the initial steps in any effective risk management strategy is to accurately measure market risks. Portfolio diversification, the tool most often used to protect investments during financial crises, relies on it. Currently, quantitative methods are commonly used in risk management; and there is a vast financial literature about different techniques to measure market risks (e.g., Britten-Jones and Schaefer, 1999; Berkowitz and O'Brien, 2002; and Guidolin and Timmermann, 2006). ${ }^{1}$ However, all approaches assume a complete price dataset; and thus they do not take into account portfolios with incomplete historical data of prices due to infrequently traded assets. ${ }^{2}$ Infrequent (or thin) trading is pervasive and deeply affects all financial markets worldwide. Infrequent trading is very common in emerging markets (e.g., Lim et al., 2009); but it is also observable in some assets in well developed markets such as the NYSE (e.g., Roll et al., 2007), the Canadian stock market (e.g., Boabang, 1996), or the stock option market at the CBOE (e.g. Chan et al., 2002). The infrequent trading problem has been typically dealt by practitioners through the replication of the price of last transaction until that a new price appears (which is equivalent to assume that the daily returns are equal to zero for the days without prices). Nevertheless this practice could generate biases (e.g., Kallunki, 1997) or autocorrelations, which could affect the mean reversion processes of the assets (e.g, Millet et al., 1994). Surprisingly, however, the literature exploring market risk measures for portfolios within an environment of infrequent trading appears to be rather limited. Therefore, the

$1 \quad$ See Duffie and Pan (1997); Manganelli and Engle (2001); or Christoffersen (2003) for a review of risk measures

2 Only risk measures based on option implied volatilities do not use historical information (where the securities that need risk measures are the underlying assets of the options). However, few assets have options traded in option markets. Moreover, the high volume traded on the underlying securities (which is not a characteristic of assets with infrequent trading) is one of the main selection factors applied by options exchanges to choose a security and thus to introduce option contracts using it as an underlying asset (see Mayhew and Mihov, 2004). 
main purpose of our study is to fill this gap by introducing a methodology to measure market risks on portfolios with thinly traded securities.

We use one of the most popular market risk measures in banking and finance: the Value-at-Risk ( $V a R)$. The $V a R$ is a popular measure because it answers the following simple question: given the probability $\alpha$, what is the expected loss of an asset (or portfolio) over a time interval? The VaR has the property that risk is expressed in monetary units, which is simple and easy to understand. In addition, the VaR is not only used for portfolio management strategies. The $V a R$ is also particularly critical in the financial sector where regulatory agencies periodically require financial institutions to report their risk exposures, in order to set up their minimum capital levels of reserves (e.g., Jackson et al., 1997; and Pérignona and Smith, 2010). ${ }^{3}$ For instance, if the VaR is underestimated, then there are high chances of incurring large losses and penalties that may come from regulatory agencies. Conversely, overestimations of the VaR may lead financial institutions to retain unnecessary reserves implying high costs of capital.

We propose a methodology based on three stages. First, we obtain a complete price dataset using an asset pricing model estimated by the Kalman filter with the incomplete panel of prices. In this stage, we estimate the asset pricing model to characterize prices and thus to generate a complete historical dataset of model prices and returns. The Kalman filter is a well-known recursive method to estimate the parameters in dynamic models, which can also be used in environments with incomplete panels by a simple adjustment. The most important characteristic of the Kalman filter is that we are able to obtain an estimation of a pricing model even for days with very few price observations. Second, we estimate the market risk measures with the complete panel data of prices generated in the first stage. Since in the implementation of our methodology we use VaR measures, we calculate them by eight different methods and in different sub-periods as robustness checks. Third, we back-test the market risk measures with the original incomplete historical panel of observable prices to verify the reliability of the estimates. In our implementation, we should observe that the percentage of times in which losses exceed the calculated VaR values to be close to the confidence level $\alpha$ at which the VaR measures were estimated. We propose an $a d$-hoc procedure to make efficient use of all the available information in the back-testing process. The main advantage of the ad-hoc procedure is that allows us to back-test the complete portfolio with thinly traded assets; which is essential for asset allocation strategies. ${ }^{4}$

3 See Basel Committee (1996a, 1996b) for a regulatory perspective.

4 In our initial attempts to find risk measures in a thinly traded environment, we directly used the Kalman filter to estimate the VaR measures with the incomplete panel of market prices (i.e. without using an asset pricing model to generate an initial complete dataset; or equivalently without Stage I). However, our results improved significantly when we incorporated an asset pricing model to obtain the complete panel of prices (i.e. Stage I). This is due to the fact that asset pricing models describe assets very well, since that is their objective; which is very useful to characterize prices when there are no transactions. The reason why asset pricing models are good to describe prices could be due to: the use of these models by investors (a self-fulfilling prophecy); because the prices are effectively well characterized by them, or a combination of both. 
As an example of thinly traded securities, to implement our methodology we use data on Chilean governmental bonds traded in the Santiago Stock Exchange to construct a portfolio of 20 bonds with different maturities. However, our approach can also be applied to other markets where infrequent trading exists, especially where pricing models can be estimated by the Kalman filter. ${ }^{5}$ In those markets, risk management measures may be also calculated for portfolios with thinly traded assets by using the Kalman filter in a similar way to our approach.

There are some studies related to ours, but they do not investigate market risk measures in an environment of thin trading. Moscadelli et al. (2005) and Chernobai et al. (2006) investigate the problem of incomplete data but only from the perspective of operational VaR measures. Bartholdy and Riding (1994), Martikainen et al. (1996), Boabang (1996), and Sercu et al. (2008) explore the influences of thin trading on asset pricing models. Antonios et al. (2002) and Lim et al. (2009) show how infrequent trading could affect market efficiency. Cortazar et al. (2007, 2012) study the term-structures of interest rates and of corporate bond spreads, in scenarios of thin trading. Finally, Bassett et al. (1991) and Jokivuolle (1995) present econometric tools to calculate stock indexes in an environment of incomplete panels of prices.

Our methodology offers reliable $V a R$ measures for thinly traded markets using out-of-sample (one-day ahead) tests. We obtain comparable levels of VaR measures in relation to previous studies, which use similar markets to the one used in our implementation but with complete panel of prices (e.g., Kiesel et al., 2000; Fernandez, 2003; Bao et al., 2006; and Fernandes et al., 2008). Moreover, we show that the best $\mathrm{VaR}$ methods to describe the market risk in an environment with thinly traded assets are those that characterize the left tail of the conditional distribution modeling heteroskedastic financial return series (e.g. heteroskedastic extreme value methods using the generalized Pareto distribution). These results are also similar to the outcomes of earlier studies with complete panels of prices (e.g., Fernandez, 2003; Kuester et al., 2006; and Bao et al., 2006), which supports the consistency of our methodology.

Consequently, we contribute to the body of knowledge exploring market risks in environments with portfolios including infrequently traded assets. To the best of our knowledge, there is no literature where market risk measures have been investigated in the context of thin trading. Therefore, the focus of our paper on the examination of asset risk management on portfolios within infrequent trading scenarios appears distinctive. The paper is organized as follows. The data used in the implementation of our methodology is introduced in Section 2. Section 3 presents the proposed methodology and describes the implementation on a thinly traded portfolio. Section 4 shows robustness checks evidencing the superiority of the proposed methodology with respect to alternative strategies used to deal with thin trading environments. Lastly, conclusions are drawn in Section 5.

$5 \quad$ For instance, there are studies about pricing models that use the standard Kalman filter for stock markets (e.g. Brennan et al., 2005; and He et al., 2010); and for option markets (e.g., Bedendo and Hodges, 2009). 


\section{The DAta}

We implement our methodology with daily data for the main governmental bonds in the Chilean fixed income market. We use semi-annual coupon bonds, called PRCs ("Pagare Reajustable con Cupones") traded between January 4, 1999 and December 30, 2005 (1749 trading days). PRCs are inflation-protected bonds issued by the Central Bank of Chile, which are traded at the Santiago Stock Exchange. ${ }^{6}$ A portfolio comprising 20 PRC bonds with different maturities ranging from one to twenty years is created to implement our methodology. The portfolio is constructed with the assumption that $\$ 10,000$ is invested in each of the 20 bonds, for a total investment of $\$ 200,000$. The portfolio is re-balanced daily so the $\$ 10,000$ investment in each asset remains constant over time. Table 1 illustrates

TABLE 1

SUMMARY STATISTICS FOR PRC BONDS

IN THE SANTIAGO STOCK EXCHANGE

\begin{tabular}{|ccccc|}
\hline $\begin{array}{c}\text { Bond Maturities } \\
\text { in Years }\end{array}$ & $\begin{array}{c}\text { Number of } \\
\text { Observations }\end{array}$ & $\begin{array}{c}\text { Average Trading } \\
\text { Frequency }\end{array}$ & $\begin{array}{c}\text { Yield } \\
\text { (mean) }\end{array}$ & $\begin{array}{c}\text { Yield } \\
\text { (Stand. Dev.) }\end{array}$ \\
\hline 1 & 329 & $18.79 \%$ & $5.49 \%$ & $1.92 \%$ \\
2 & 553 & $31.64 \%$ & $5.28 \%$ & $1.86 \%$ \\
3 & 566 & $32.37 \%$ & $5.36 \%$ & $1.37 \%$ \\
4 & 876 & $50.10 \%$ & $4.57 \%$ & $1.59 \%$ \\
5 & 674 & $38.56 \%$ & $5.80 \%$ & $1.39 \%$ \\
6 & 751 & $42.91 \%$ & $5.80 \%$ & $1.25 \%$ \\
7 & 1,139 & $65.13 \%$ & $5.00 \%$ & $1.31 \%$ \\
8 & 1,408 & $80.49 \%$ & $4.80 \%$ & $1.17 \%$ \\
9 & 620 & $35.46 \%$ & $4.84 \%$ & $1.04 \%$ \\
10 & 715 & $40.87 \%$ & $5.34 \%$ & $0.84 \%$ \\
11 & 387 & $22.15 \%$ & $5.34 \%$ & $1.03 \%$ \\
12 & 603 & $34.48 \%$ & $5.55 \%$ & $0.91 \%$ \\
13 & 384 & $21.95 \%$ & $5.29 \%$ & $0.95 \%$ \\
14 & 680 & $38.89 \%$ & $4.71 \%$ & $0.80 \%$ \\
15 & 446 & $25.51 \%$ & $4.95 \%$ & $0.96 \%$ \\
16 & 483 & $27.62 \%$ & $4.84 \%$ & $0.82 \%$ \\
17 & 398 & $22.74 \%$ & $4.71 \%$ & $0.75 \%$ \\
18 & 487 & $27.82 \%$ & $5.18 \%$ & $0.96 \%$ \\
19 & 794 & $45.42 \%$ & $5.11 \%$ & $0.98 \%$ \\
20 & 940 & $53.72 \%$ & $4.98 \%$ & $0.98 \%$ \\
\hline
\end{tabular}

Notes: The sample period is January 4, 1999 to December 30, 2005. Trading frequency is defined as the number of days for which there is at least one transaction of a given bond over all available trading days. The yields are continuously compounded.

6 In practice the inflation adjustments are achieved by expressing the coupons in a different unit rather than the Chilean peso: the $U F$ ("Unidad de Fomento"), which is updated daily using the previous month's variation of the Chilean consumer price index. 
the missing data problem in this market by presenting the trading frequency of $P R C$ bonds in our portfolio during the whole sample period. Trading frequency is defined as the number of days in which we have at least one transaction of a bond with a specif ic maturity over all available trading days. A trading frequency of $10 \%$ means that a security is traded on average 25 days per year. In addition, Table 2 presents a sub-sample of daily traded bond prices between March 20, 2000 and May 15, 2000, where black spaces represent days on which the security was not traded. Table 2 provides a clear illustration of the incomplete panel problem.

\section{The Methodology and Implementation on a Thinly Traded Portfolio}

\section{Stage I: Generation of a Complete Panel of Prices}

Our methodology is based on three stages which allow us to obtain market risk measures of portfolios in an environment with infrequently or thinly traded assets. In the first stage, we generate a complete historical dataset of prices for the portfolio which are inputs necessary to calculate market risks. Therefore, as a first step we estimate an asset pricing model using the Kalman filter to characterize prices. However, following Cortazar et al. 2007, we adjust the standard Kalman filter technique to deal with an incomplete panel of bond prices, as has also been done for other markets like market indices (Basset and Hodges, 2009) or commodities (Cortazar et al. 2006, 2008). In our implementation we use the Kalman filter to estimate on a daily basis a multifactor dynamic term-structure model of the interest rate using a rolling window.

Traditional estimation approaches for models characterizing the term-structure of the interest rates require a minimum number of different observable bond prices at a given time $t$ (i.e. bonds with different maturities). ${ }^{7}$ An example in which the utilization of traditional estimation techniques (such as ordinary least squares, OLS; generalized least squares, GLS; among others) with thinly traded securities is precluded is when on a given day the number of parameters to be estimated for an asset pricing model is larger than the number of the observable prices on the market (i.e. we can fit infinite models to the data). For example, the Svensson's parametric model (Svensson, 1994) for characterizing the termstructure of the interest rates needs six parameters to be estimated; therefore on days with less than six different traded bonds we cannot get an estimation of this model. However, the Kalman filter allows an estimation of the term-structure of the interest rates even for days with very few price observations; since we use historical data where new information is weighted more than older ones. ${ }^{8}$ Once

7 See, e.g., Nelson and Siegel (1987) and Svensson (1994) for parsimonious functional structures, Vasicek (1977), Cox et al. (1985), and Duffie and Kan (1996) for dynamics models; and McCulloch (1971) and Vasicek and Fong (1982) for spline curve-fitting models.

8 For a review of dynamic term-structure interest rate models using the standard Kalman filter (without infrequent trading) see Babbs and Nowman (1999); Geyer and Pichler (1999); and Chen and Scott (2003). 


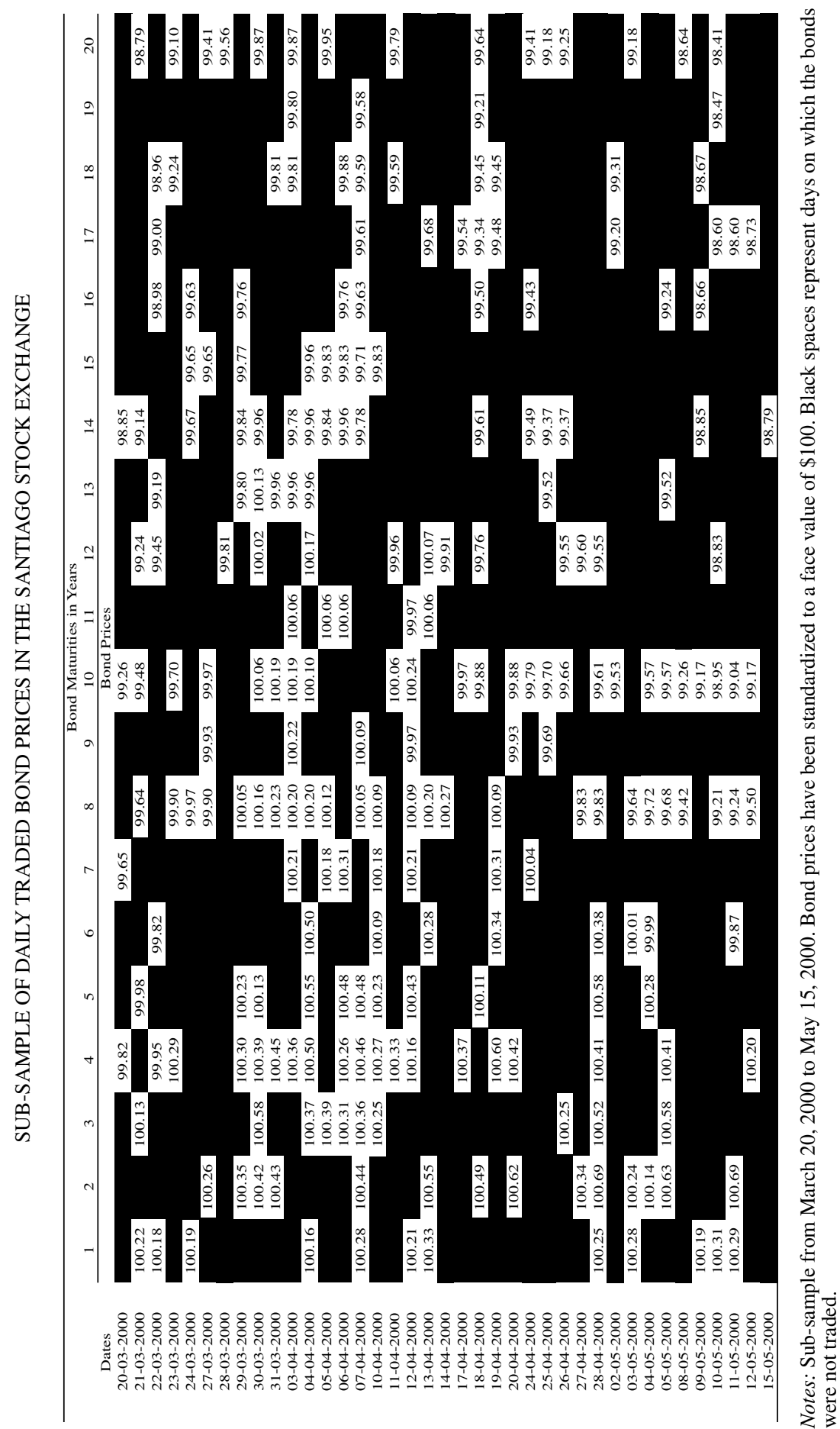


the term-structure of the interest rates model is estimated with the incomplete dataset, we use the daily zero curves to compute discount factors and hence prices of bonds in the investment portfolio generating a complete panel of fair prices. ${ }^{9}$

In the implementation, we use a three-factor generalized Vasicek model to characterize the term-structure of the interest rates, which is a mean-reverting Gaussian specification of the instantaneous spot interest rate which extends the classic Vasicek's (1977) dynamic model. We select this model for its simplicity as a dynamic representation for the term-structure of the interest rates, and for its flexibility given the three factors that allow diverse shape forms. The simplicity of this model allows us to explain in a very simple way the Kalman filter technique in an environment of infrequent trading. ${ }^{10}$ It is important to mention that the Vasicek models assume a constant volatility of the instantaneous interest rate, which could contradict the main purpose of finding risk measures that depend of the volatility of bond prices. However, we estimate each day this multifactor dynamic term-structure model; and thus the volatility of the interest rate can change over time. A reader can consider this procedure as an attempt of replicating typical practices in the market, such as the use of the Black and Scholes' (1973) model that assumes a constant volatility of the underlying asset; nevertheless practitioners obtain through this option model daily implied volatilities which change over time, the strike price, and the time-to-maturity (see Goncalves and Guidolin, 2006).

We estimate the model using a six-month daily rolling window. Therefore, we obtain a complete data panel of fair prices that starts on July 1999 because the first 6 months of data are used in the first estimation. To obtain the fair prices, we calculate interest rates for all maturities on each day using the daily estimated model. Therefore, using this estimated yield curve, daily fair prices for all bonds in the portfolio are computed through the sum of the present value of the coupons (See Appendix A for a mathematical explanation of the model and its estimation).

\section{Stage II: Estimation of Market Risk Measures}

In the second stage, we calculate the market risk measures. Risk measures are directly related to the volatility of gains and losses, therefore the relevant complete historical dataset is the one that includes returns (specifically, log-returns). We use a historical panel of returns calculated with only fair prices to estimate the market risk measures. The use of data from different sources to calculate returns (i.e. a mixed panel with traded prices and fair prices on dates where assets are not traded) could imply additional noise in the return values; and therefore a mixed dataset could disturb market risk estimations. For instance, we show in Appendix

9 For a review of the Kalman filter see Harvey (1982), Davis (1982), and Simon (2006).

10 In addition, our methodology can be implemented with other dynamic models. For instance, there other simple models for the term-structure of the interest rates such as the model introduced by Cox et al. (1985) or other specifications. In particular, we did not use the Cox et al. (1985) model because the volatility is multiplied by the squarer root of the interest rate that implies that interest rates cannot be negative, which is a problem when using 'real' instead of 'nominal' interest rates, as we are. 
B that fair prices could be significantly biased in relation to observable data due to different liquidity premiums among securities depending of liquidity levels. ${ }^{11}$ The reason is that all asset pricing models, even those estimated dynamically like the one implemented in our study, on average replicate the behavior of prices. Therefore, consistently liquid (illiquid) securities might be underestimated (overestimated) due to differences in the liquidity premiums. For that reason, returns calculated with a mixed panel of fair and market prices could generate additional disturbances in the estimations. However, in Appendix B we also show that there are no biases between returns calculated with only fair prices in relation to returns calculated with only market data, since the 'levels' issues are eliminated. The intuition behind unbiased returns is simple. Even though fair prices are biased, movements or changes in fair and market prices are going in the same direction and following similar paths (i.e. the dynamic model captures the market movements since it is estimated daily). Consequently, given that the fair prices were biased but fair returns were not, then it is better to make use of returns calculated with only fair prices to estimate the market risk. ${ }^{12}$

In the implementation of our methodology we use the $V a R$ as the market risk measure. The VaR quantifies the risk of a loss in an investment within a time interval and for a given confidence level. More precisely, let $w_{t+\Delta t, t}$ be the variation in value of an investment resulting from the price variation in the time interval $\Delta t$, and $f\left(w_{t+\Delta t, t}\right)$ the unknown probability density function of such variations. The $V a R$ of an asset (or portfolio of assets), is the amount of money that could be lost from negative events which could occur with a probability $\alpha$. Thus, the VaR can be computed as:

$$
P\left(w_{t, t+\Delta t} \leq \operatorname{VaR} R_{t, t+\Delta t} \mid F_{t}\right)=\alpha
$$

or,

$$
\int_{-\infty}^{\operatorname{VaR}_{t, t+\Delta t}} f\left(w_{t, t+\Delta t} \mid F_{t}\right) d w=\alpha
$$

where $F_{t}$ is the information set until day $t$. For example, if the VaR is calculated at a confidence level of $5 \%$, there is a chance of $5 \%$ that an actual loss may exceed the value provided by the VaR. ${ }^{13}$ There are three main groups of methods to calculate VaR. First, VaR methods that assume a known distribution for the security returns; second, the non-parametric VaR methods; and third, Monte Carlo simulations. In the implementation of our methodology, we use at least one method from each group as a robustness check. ${ }^{14}$ We use eight different

11 See Chen et al. (2007) for liquidity effects of bond premiums.

12 In Appendix B, we analyze the prices biases and the returns unbiasness using the complete sample and sub-samples as robustness checks.

13 For example, a $\mathrm{VaR}_{5 \%}=\$-300,000$ on an investment is equivalent to saying that a loss of $\$ 300,000$ (or more) can be expected on five days out of one hundred days.

14 See Duffie and Pan (1997), Manganelli and Engle (2001), and Jorion (2006) for additional details about $V a R$ measures. 
methods to estimate these risk measures (the methods are explained in detail in Appendix C): the VaR method of variance-covariance; the VaR method of exponential decay (RiskMetrics ${ }^{\mathrm{TM}}$ ); the VaR GARCH method; the VaR t-student distribution method; the $V a R$ extreme value theory method (static version); the VaR extreme value theory method (dynamic version); the VaR historical simulation method; and the VaR Monte Carlo simulation method.

\section{Stage III: Back-Testing with an Incomplete Data Set of Market Prices}

In the third stage, a back-testing procedure for the market risk measures is required. However, a well-performed back-test has to be based on the historical observable market data. In our implementation, the back-testing procedure for a VaR method lies in computing the percentage of times in which daily losses of an investment at time $t$ have been larger than the one estimated by VaR values at time $t$-1. This percentage should not be significantly different from the confidence level $\alpha$ under which the $\mathrm{VaR}$ measures are calculated. In our study, the back-testing has two main purposes. First, to observe the reliability of the VaR measures obtained with the proposed methodology. The analysis of the reliability of our approach is a key issue since with the back-testing we can analyze statistically whether our methodology can capture the market risk. Moreover, a reader may interpret the back-testing exercise as a way of testing our approach in a real environment of infrequent trading. Secondly, the back-testing allows us to detect the best VaR method for characterizing the market risk for the tested portfolio in an environment with thinly traded assets.

In the back-testing, for example, a perfect $V a R$ method calculated daily with $5 \%$ confidence level should report that $5 \%$ of the time losses exceeded the values provided by the VaR estimations in the previous day. Therefore, a proper backtesting procedure of the VaR implies an out-of-sample (one-day ahead) testing process. We use the Kupiec (1995) test that analyzes the historic percentage of losses exceeding the VaR. The null hypothesis states that, the proportion of losses beyond the $V a R$ is equal to $\alpha$. Consequently, if the null hypothesis is not rejected, the VaR method involved in the back-testing is inside a confidence interval with a confidence level $\beta$ defined in the Kupiec (1995) test. In our implementation, as a first step, we back-test the VaR measures using the standard approach introduced in previous literature (e.g., Jorion, 2006; Pritsker, 2006; and Kawata and Kijima, 2007); and then we propose an ad-hoc procedure that makes use of all the available information.

As we mentioned previously, a well-implemented back-testing has to be done with historical prices traded in the market. In the back-testing procedure for daily $V a R$ measures, we need sets of two successive days where prices are observed to account for daily gains or losses in the value of the security. However, in an environment with thinly traded assets this is unusual. For instance, an infrequently traded security with observable price on day $t$ but nothing on day $t-1$ implies that in the time series of returns we do not have data for days $t$ and $t$ - 1 (i.e. not only at $t-1)$. Consequently, incomplete panels of historical prices generate more incomplete panels of historical returns. This issue is even more complicated in a portfolio with various thinly traded assets because it is likely that every day at least one of them does not have a traded price (see, e.g., Table 2). Therefore, with 
incomplete panels of returns and following traditional back-testing approaches, we could only test VaR methods for each bond individually in the portfolio using the panel of observable daily returns (i.e. returns calculated with observable prices on days $t$ and $t+1$ ).

Nevertheless, we propose an ad-hoc back-testing following a simple procedure that makes efficient use of all available data. Moreover, the main advantage of our ad-hoc procedure is that a back-testing of the complete portfolio can be performed even with a range of thinly traded assets. The back-test of the complete portfolio is an essential part for the asset allocation, since it is necessary to consider correlations between assets, which are a fundamental part of diversification, and risk management. This ad-hoc back-testing procedure is explained in the following paragraphs, and subsequently we present results applied to our implementation. 15

We assume that an amount $M$ is invested in a single asset on day $t$, and during the subsequent $d$ days the asset is not traded. Therefore, two consecutive prices for the asset are observed at times $t$ and $t+d+1$ (i.e. $P_{t}$ and $P_{t+d+1}$, respectively). The key issue is how to use this multi-day price return in order to compare it with an estimate of a daily VaR measure. Let $V a R_{t+d, t+d+1}$ be the one-day $\operatorname{VaR}$ measure under a confidence level $\alpha$ for the day $t+d+l$ given all the information observable on the previous day $F_{t+d}$; while $w_{t+d, t+d+1}$ is the variation in value between $t+d$ and $t+d+1$, then:

$$
P\left(w_{t+d, t+d+1} \leq V a R_{t+d, t+d+1} \mid F_{t+d}\right)=\alpha
$$

where

$$
w_{t+d, t+d+1}=\left[\frac{P_{t+d+1}}{P_{t+d}}-1\right] M
$$

We already have the value of $\operatorname{VaR}_{t+d, t+d+1}$ using the first and second stages of our methodology. However, we cannot calculate $w_{t+d, t+d+1}$ since on day $t+d$ the security does not have an observable price; and hence in the back-testing procedure we cannot check if $w_{t+d, t+d+1}$ is lower (or higher) than the $V a R_{t+1, t+d+1}$. The basic idea of our ad-hoc back-testing procedure is to use the previous observable price $P_{t}$ together with all the new information until $t+d\left(F_{t+d}\right)$ which is captured by the asset pricing model estimated in the first stage. Therefore, we calculate estimates of $P_{t+d}$ using the prior trade price $P_{t}$ given $F_{t+d}$ as:

$$
\ln \left(\frac{P_{t+d}}{P_{t}}\right) \approx \ln \left(\frac{\hat{P}_{t+d}}{\hat{P}_{t}}\right) \Rightarrow \tilde{P}_{t+d \mid F_{t+d}} \approx P_{t} \cdot \frac{\hat{P}_{t+d}}{\hat{P}_{t}}
$$

where $\hat{P}_{t}$ and $\hat{P}_{t+d}$ are fair prices. ${ }^{16}$ Consequently,

15 See Hyung and de Vries (2007) for portfolio diversification effects on VaR measures.

16 We empirically support this assumption in Appendix B. 


$$
\tilde{w}_{t+d, t+d+1}=\left[\frac{P_{t+d+1}}{P_{t} \cdot \frac{\hat{P}_{t+d}}{\hat{P}_{t}}}-1\right] M
$$

It is interesting to observe that $\tilde{w}_{t+d, t+d+1}$ is calculated with two observable prices $\left(P_{t}\right.$ and $\left.P_{t+d+1}\right)$ jointly with all the information available on the day $t+d$ given by $F_{t+d}$. This ad-hoc procedure allows us to compare daily $\operatorname{VaR}_{t+d, t+d+1}$ with estimates of the daily gains (or losses) $\tilde{w}_{t+d, t+d+1}$ which incorporate all the information at each instant. ${ }^{17}$

Table 3 presents results of the back-testing for different VaR methods with $\alpha=5 \%$ in our implementation using the portfolio of Chilean bonds for the complete sample. Table 3 Panel A shows the results of the back-testing for VaR methods estimated individually for each bond using daily returns calculated with the original panel of observable prices (i.e. daily returns are calculated with only successive prices that take place at $t$ and $t+1$ ). Table 3 Panel B and Panel C report the results of the back-testing procedure using our ad-hoc approach for each bond individually and for the complete portfolio, respectively. We also include three additional measures for back-testing purposes. We calculate the average $V a R$ over the whole time period. The average $V a R$ is particularly relevant for regulated institutions which are required to maintain capital levels that dependent on their reported $\mathrm{VaR}$ measures (e.g. commercial banks). For these institutions, a large average VaR implies high costs of capital; in contrast, lower values could imply a rejection of the null hypothesis in the Kupiec test and therefore penalties from regulatory agencies. Furthermore, we include the average excess over the $V a R$, which is similar to the 'Conditional Value-at-Risk' (CVaR). The CVaR is the average loss conditional on losses greater than the calculated VaR; and thus the $C V a R$ exceeds our measure (the average excess over $V a R$ ) by an amount equal to the average $V a R .{ }^{18}$ Additionally, we include the maximum excess over $V a R$ to see how catastrophic such event could be relative to VaR estimates. In Appendix D Table D.1 and Table D.2, we report the same analysis as Table 3 but using two different sub-samples as robustness checks.

Table 3 Panel A shows that the results observed in that back-testing are similar to those presented using our ad-hoc procedure for individual bonds and the complete portfolio in Table 3 Panel B and Panel C, respectively. However, the $a d$-hoc procedure makes more efficient use of all the information available at each instant. Moreover, the $a d$-hoc procedure allows the back-testing of the complete portfolio which is extremely important to evaluate the risk of all assets at the same time; and thus taking into account asset correlations. For instance, the average $V A R$ for the portfolio (see Table 3 Panel C) is lower than the average $V A R$ for individual bonds multiplied by 20 (see Table 3 Panel A and Panel B) due to the effect of correlations. In addition, Table 3 shows that the best VaR

17 Of course, in the case of observing prices on two successive trading days (i.e. $d=0$ ), we calculate the $w_{t, t+1}$ in the traditional way as $w_{t+d, t+d+1}=\left[P_{t+1} / P_{t}-1\right] M$.

18 For a review of the CVaR see Rockafellar and Uryasev (2000, 2002). 


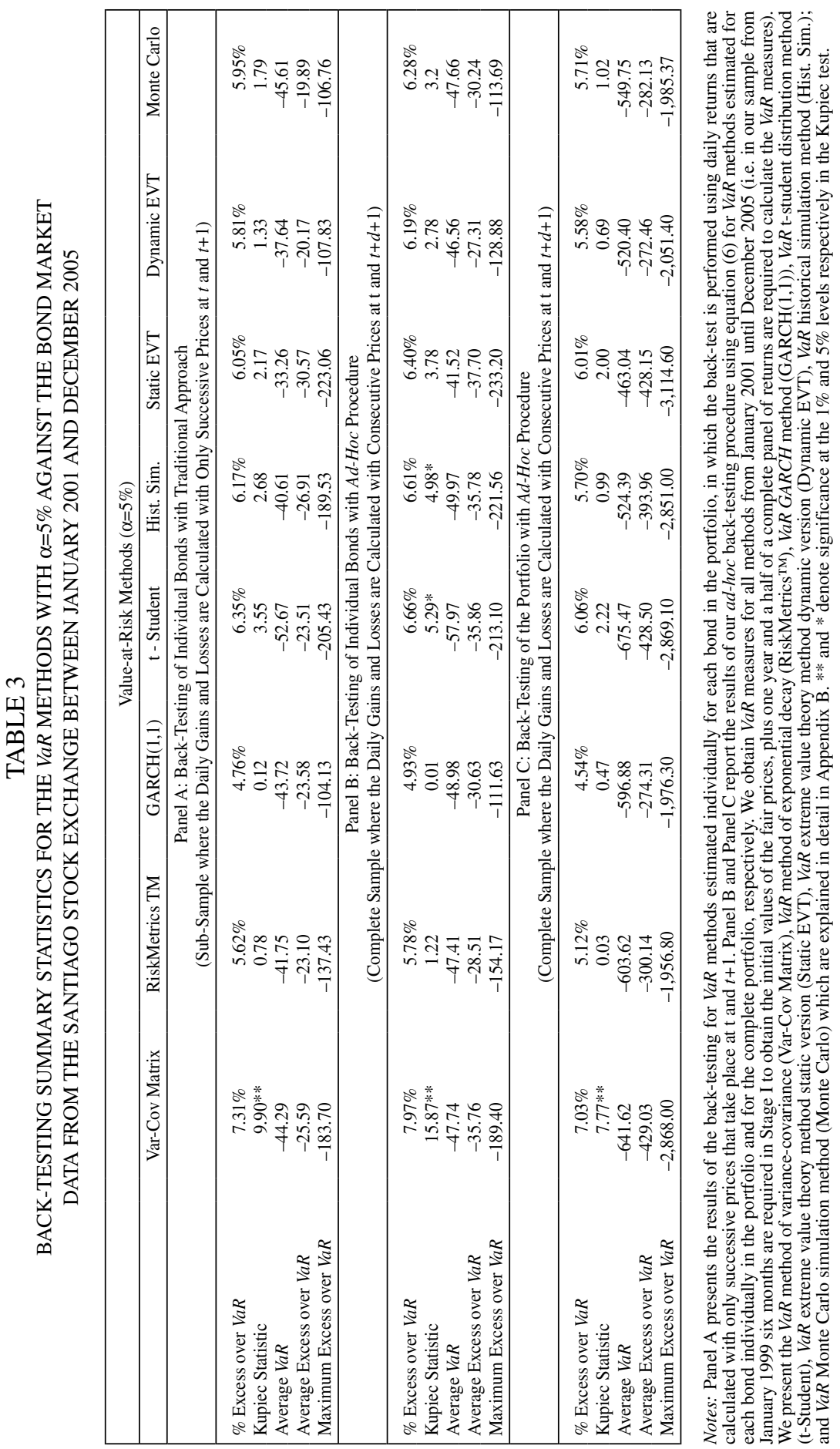


methods for a confidence level of $5 \%$ are the $\operatorname{GARCH}(1,1)$, the RiskMetrics ${ }^{\mathrm{TM}}$, and the dynamic Extreme Value Theory (EVT) methods, in which the percentage of losses exceeding the $\mathrm{VaR}$ are very close to the 5\% confidence level required. The variance-covariance method offers a poor performance in which the null hypothesis of no differences between $\alpha$ and the proportion of losses under the VaR is rejected by the Kupiec test.

Furthermore, Table 3 shows that the lowest average $\mathrm{VaR}$ values are provided by the EVT methods; and thus they should be attractive for institutions that are concerned about effective but low VaR estimations implying lower capital requirements. Table 3 also reports that the average excess over the VaR of the dynamic $E V T$, the Monte Carlo, and $\operatorname{GARCH}(1,1)$ methods are slightly better than others. The latter methods provide relatively smaller excesses over the $V a R$ showing that these have performed well in capturing market dynamics.

Table 4 repeats the back-testing analysis presented in Table 3 but for VaR estimations at the $1 \%$ confidence level with our complete sample. Table D. 3 and Table D.4 in Appendix D shows the same analysis as Table 4 but using two different sub-samples to check for robustness. In Table 4 and similar to the results observed in Table 3, the back-testing calculated by the standard approach (Table 4 Panel A) reports comparable results to our ad-hoc procedure (Table 4 Panel A and Panel B). Additionally, we can observe that the only method which is not rejected by the Kupiec test is the dynamic EVT. This means that for practically all the $V a R$ methods, the average percentage of excesses over the $V a R$ is significantly different from $1 \%$. The poor performance of diverse VaR methods, with exception of the dynamic $E V T$ at the 1\% level, suggests the importance of adequately modeling the left tail of the return distributions. However, the left tail is not the unique important feature given that, in such case, the static EVT or the historical simulation methods should also offer good results. Therefore, it appears that it is also important to account for the time varying volatility of returns. For instance, Table 4 shows that although the $\operatorname{GARCH}(1,1)$ method was rejected by the Kupiec test, this method performs relatively better than methods such as the static $E V T$ and historical simulation.

It is worth noting that the poor performance of $\mathrm{VaR}$ methods at the $1 \%$ confidence level has already been documented in several studies for both emerging and developed markets, in which (as is the case with our study with the dynamic $E V T)$ the exceptions are the methods that take into account both the left tail behavior and the heteroskedasticity of the returns. Fernandez (2003) finds that the dynamic EVT methods perform best using Chilean market data (but with a complete panel of prices). Fernandes et al. (2008) analyze VaR measures for 41 countries, where they show the superior performance of $E V T$ methods. In addition, Kiesel et al. (2000) provide an analysis for emerging markets using Brady bonds reporting similar measures to those presented in our study for $\mathrm{VaR}$ measures at $5 \%$ and $1 \%$ confidence levels. Finally, Bao et al. (2006) evaluate VaR models for Asian emerging markets (Korea, Indonesia, Malaysia, Taiwan, and Thailand). Their conclusions are also similar to ours for both $5 \%$ and $1 \%$ confidence levels. ${ }^{19}$

In summary, the back-testing procedure suggests that our methodology provides accurate measures to capture the market risk, which was performed

19 Also notice that in environments with thin trading becomes harder to have extreme values and, therefore, tail estimates (at the $1 \%$ level or lower) might not be reliable by construction. 


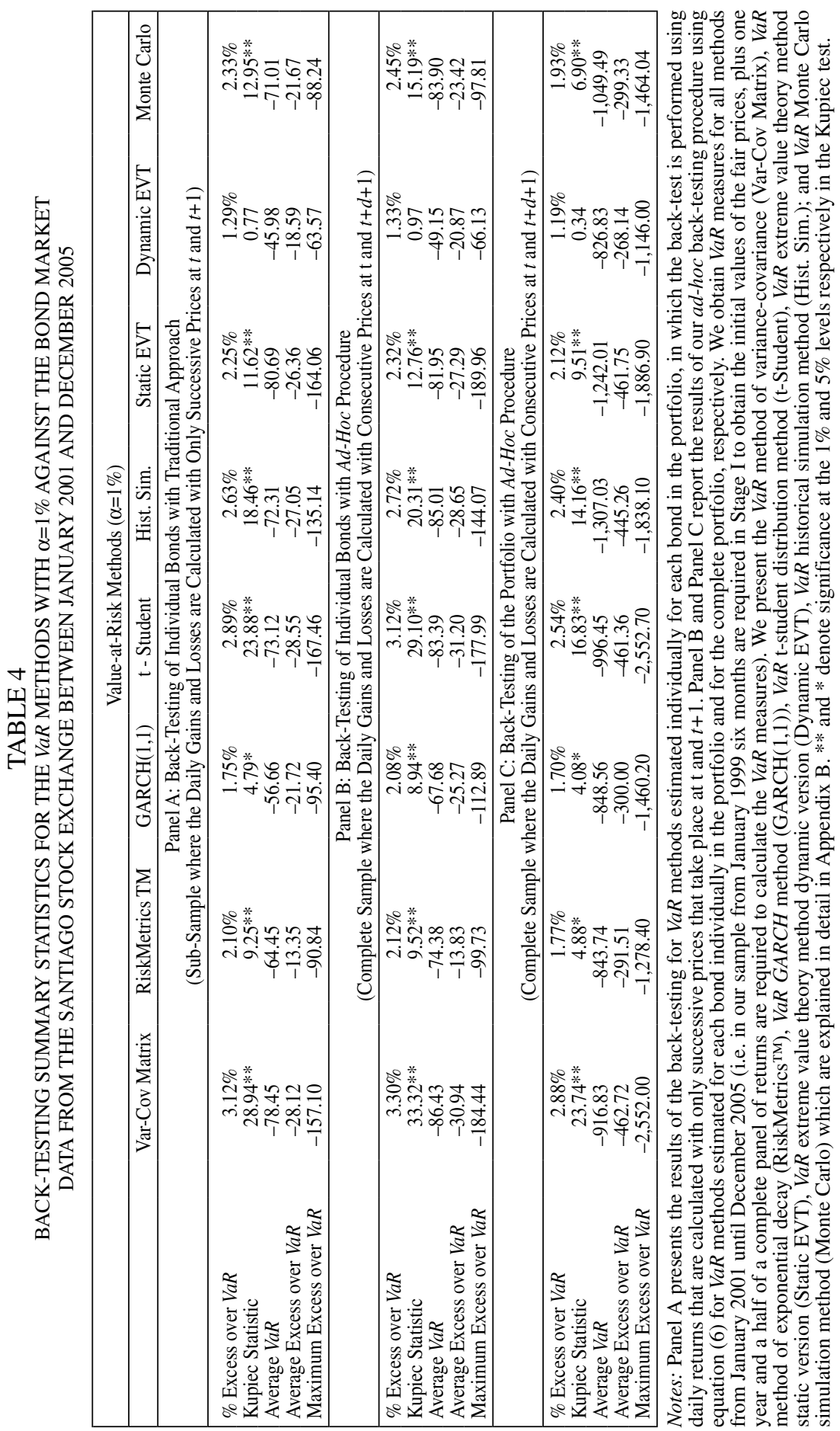


in a real environment of infrequent trading using Chilean governmental bonds. Moreover, although previous studies did not address the problem of incomplete panels of prices, their results regarding the alternative VaR methods at different confidence levels are similar to those presented in our research supporting the reliability of our methodology.

\section{Robustness Checks}

\section{The methodology of repeating the last price}

As mentioned earlier, a common practice in order to calculate VaR measures with infrequent trading is to replicate the asset's last price until a new transaction is observed. Therefore, this section provides evidence on the reliability of such practice vis-à-vis our proposed methodology. Table 5 replicates the statistics (at the 5\% confidence level) presented before but using the last traded price for each asset until a new transaction is observed. ${ }^{20}$

Panel A of Table 5 evidences that virtually all methods are rejected by the Kupiec test. This contrasts with Table 3 where using our methodology provided reliable $V a R$ measures for all methods with the only exception of the variance-covariance one. In addition, average VaRs and excesses over the VaR are also larger than the ones produced with the proposed methodology. A similar picture emerges from Panels $\mathrm{B}$ and $\mathrm{C}$. Therefore, it is apparent that the common practice of replicating the last traded prices in order to deal with infrequent trading problems is misleading. The evidence presented clearly suggests the superiority of the proposed methodology in order to deal with missing data towards calculating VaR measures. ${ }^{21}$

Changing the rolling window in the estimation of the term-structure model

So far we have been using a six-month rolling window for the estimation of the dynamic term-structure model in Stage I. However, we now explore how our methodology performs under different lengths of the rolling window. We first apply the methodology with a narrower window of three months. Notice that by shortening the window we increase by three months the panel of daily fair prices generated via the dynamic model. This provides us with more observations for the $V a R$ calculations but at the cost of less precise estimates for the dynamic model.

Table 6 displays the results for a 5\% confidence level. The results are consistent with Table 3 suggesting that the $\operatorname{GARCH}(1,1)$, RiskMetrics ${ }^{\mathrm{TM}}$, and the dynamic EVT methods perform relatively better. In addition, we also find that the variance-covariance method offers the poorest performance. However, Panel B also suggests rejection of the static EVT and the Monte Carlo method which performed relatively well when using a rolling window of six months (Table 3). The latter observation might have resulted from the less precise

\footnotetext{
20 Notice that we do not report the results of the VaR method of variance-covariance (VarCov Matrix) and the VaR Monte Carlo simulation method (Monte Carlo) since in both methods we do not obtain positive-semidefinite matrix due to the repetition of prices

21 We also conducted a similar exercise using a $1 \%$ confidence level. The results rejected all VaR methods as well.
} 


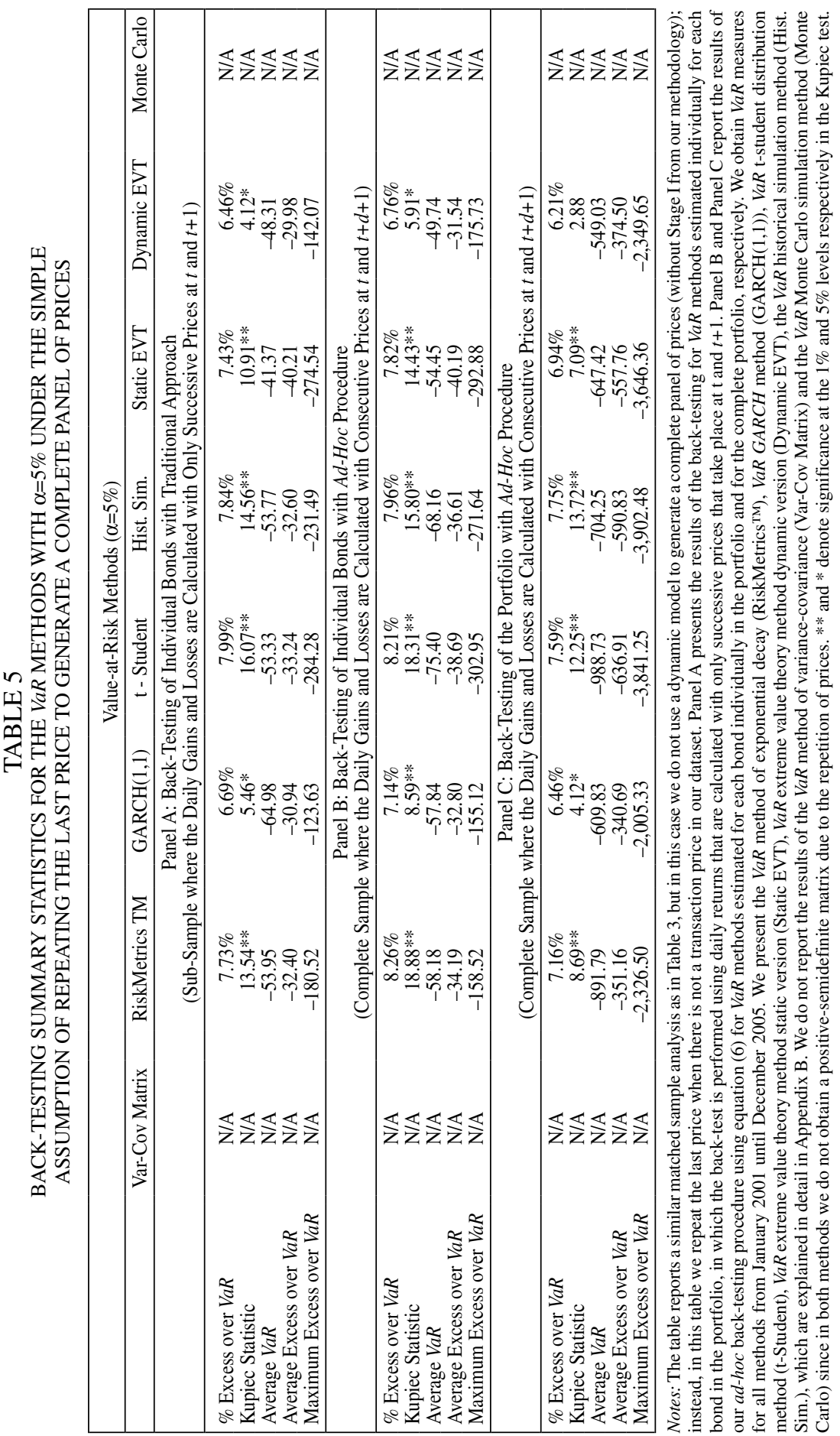




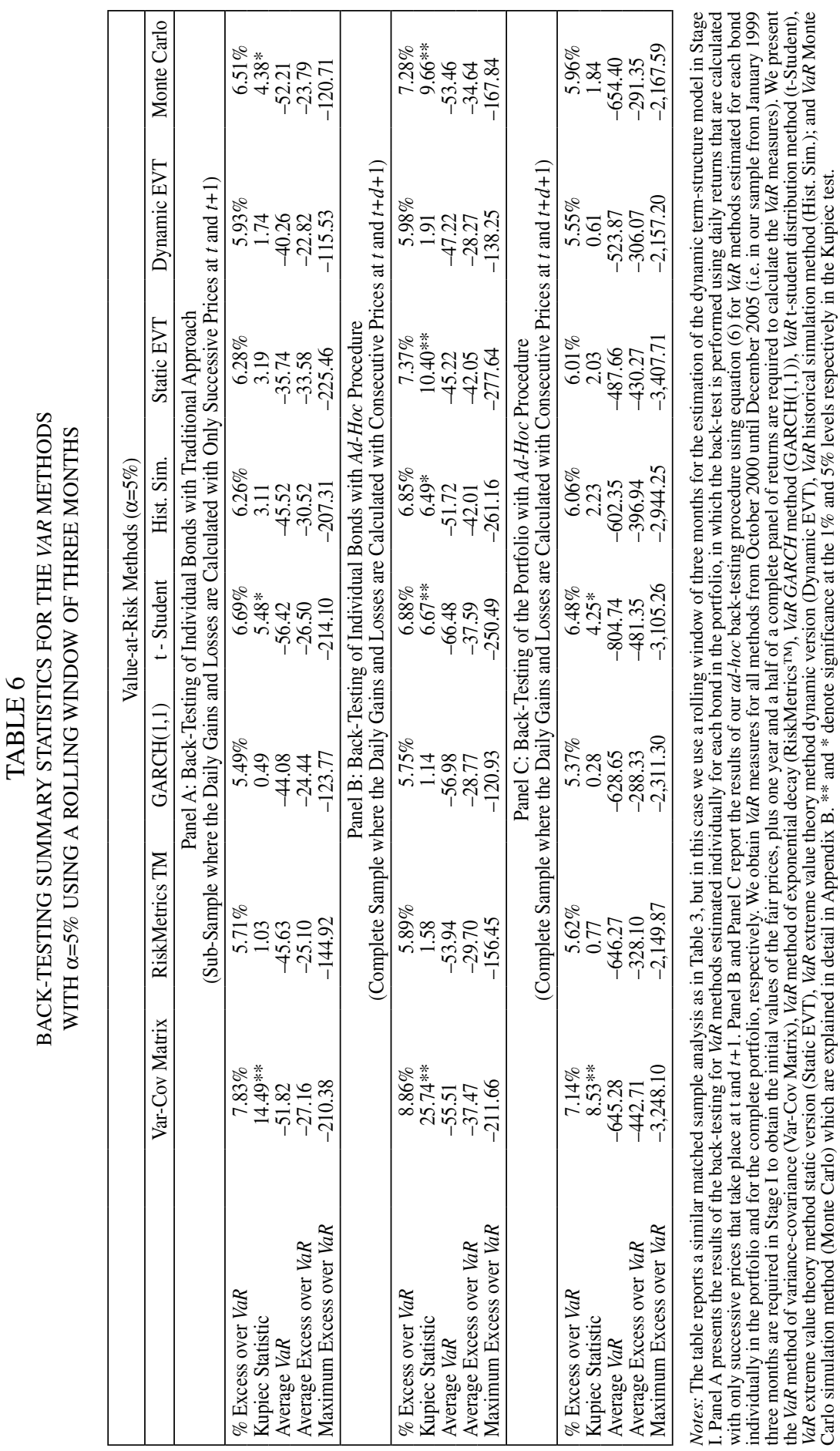


estimates obtained for the term-structure model within a shorter rolling window for its estimation.

Similarly, the rolling window could be extended. In that case, we would gain precision in estimating the dynamic term-structure model but at the cost of having a smaller panel of fair prices to calculate the VaR measures. Therefore, we extend the rolling window to 12 months with the results shown in Table 7. Overall we observe a similar pattern favoring the $G A R C H(1,1)$, RiskMetrics ${ }^{\mathrm{TM}}$, and the dynamic EVT methods. However, we also observe stronger rejections for the rest of methods (Panel B).

Overall, varying the size of the rolling window used to estimate the dynamic term-structure model leads to results that are consistent with our baseline analysis. Methods that model both the left tail of the distribution and the timevarying volatility like the $G A R C H(1,1)$, RiskMetrics ${ }^{\mathrm{TM}}$, and the dynamic $E V T$ are consistent in returning reliable VaR measures under different formats of the rolling window.

\section{A Monte Carlo Analysis for different levels of missing data}

The proposed methodology has fared well within the Chilean bond market. However, an important question is whether the methodology is externally valid. To answer such question more research in different trading markets is necessary. But to take an initial step, we simulate a bond market generating data through the estimated term-structure model. Specifically, we simulate 100 years of daily data with forward vectors of the model's state variables through its stochastic differential equation and using the average of the estimated parameters (see Appendix A). In addition, we also vary the rate of missing data (i.e. non-trading days) considering two scenarios, $60 \%$ and $30 \%$ rates of missing data. ${ }^{22}$

Tables 8 and 9 show the results for the $60 \%$ and $30 \%$ missing data rates respectively. Both tables are highly consistent suggesting a poor performance of the variance-covariance method and a relatively better performance of the $\operatorname{GARCH}(1,1)$, RiskMetrics ${ }^{\mathrm{TM}}$, and the dynamic EVT methods. ${ }^{23}$ Overall, the results suggest that our methodology offers reliable VaR measures for a simulated market and for different rates of infrequent trading.

\section{Conclusion}

Infrequently or thinly traded securities exist in all markets around the world including both emerging and developed markets. However, there is a lack of literature that explores market risk measures in portfolios with thinly traded assets. We proposed a methodology based on three stages to calculate market risks using incomplete historical panels of prices. First, we fit an asset pricing

Notice that our actual data shows a $61.37 \%$ rate of missing data.

23 Notice that the Monte Carlo VaR calculation cannot be directly compared with the one obtained in Table 3 using the historical data. This because in this exercise the artificial data is being generated with the same dynamic model than the one used to calculate the VaR measure with the Monte Carlo methodology. 


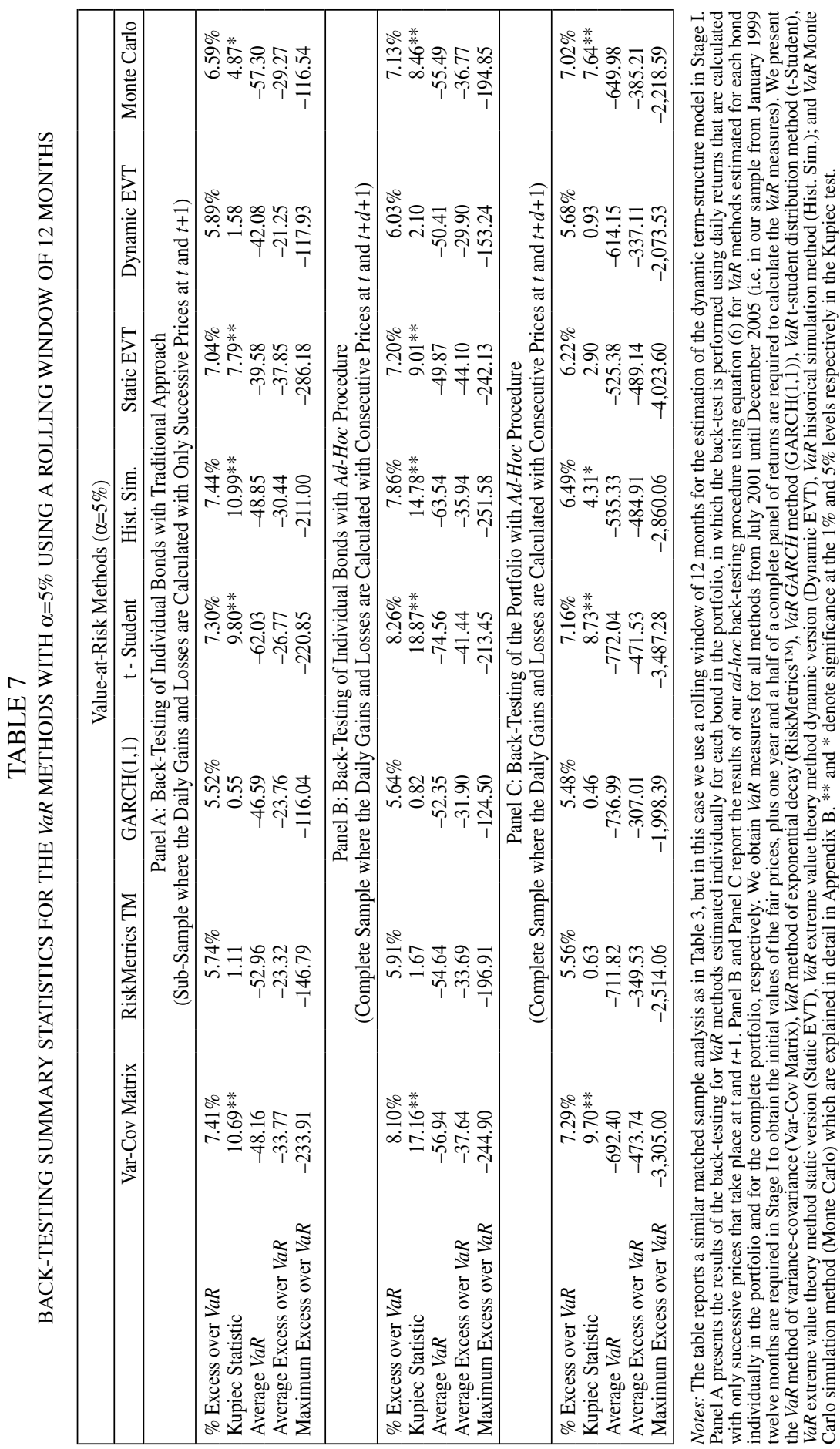




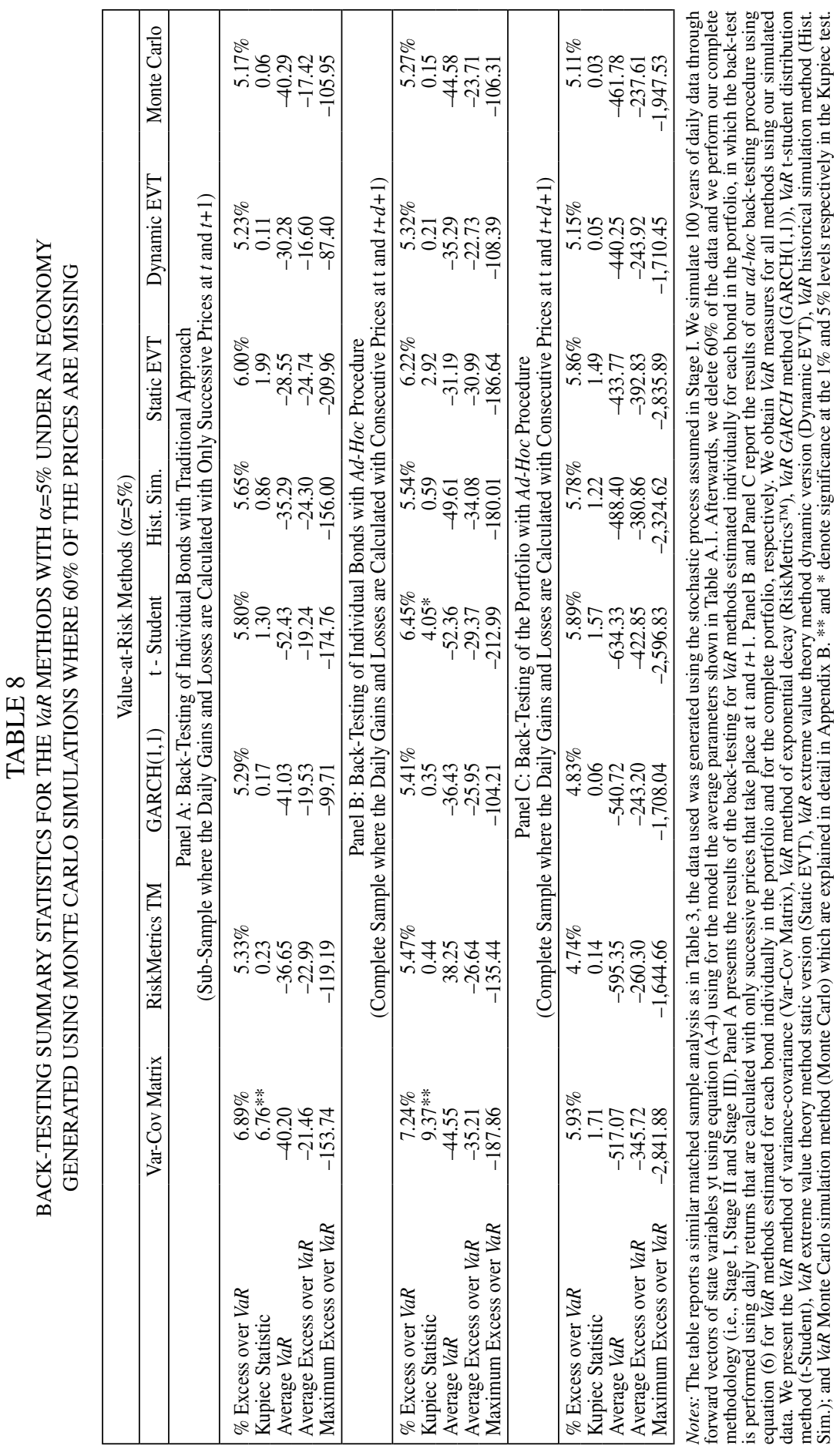




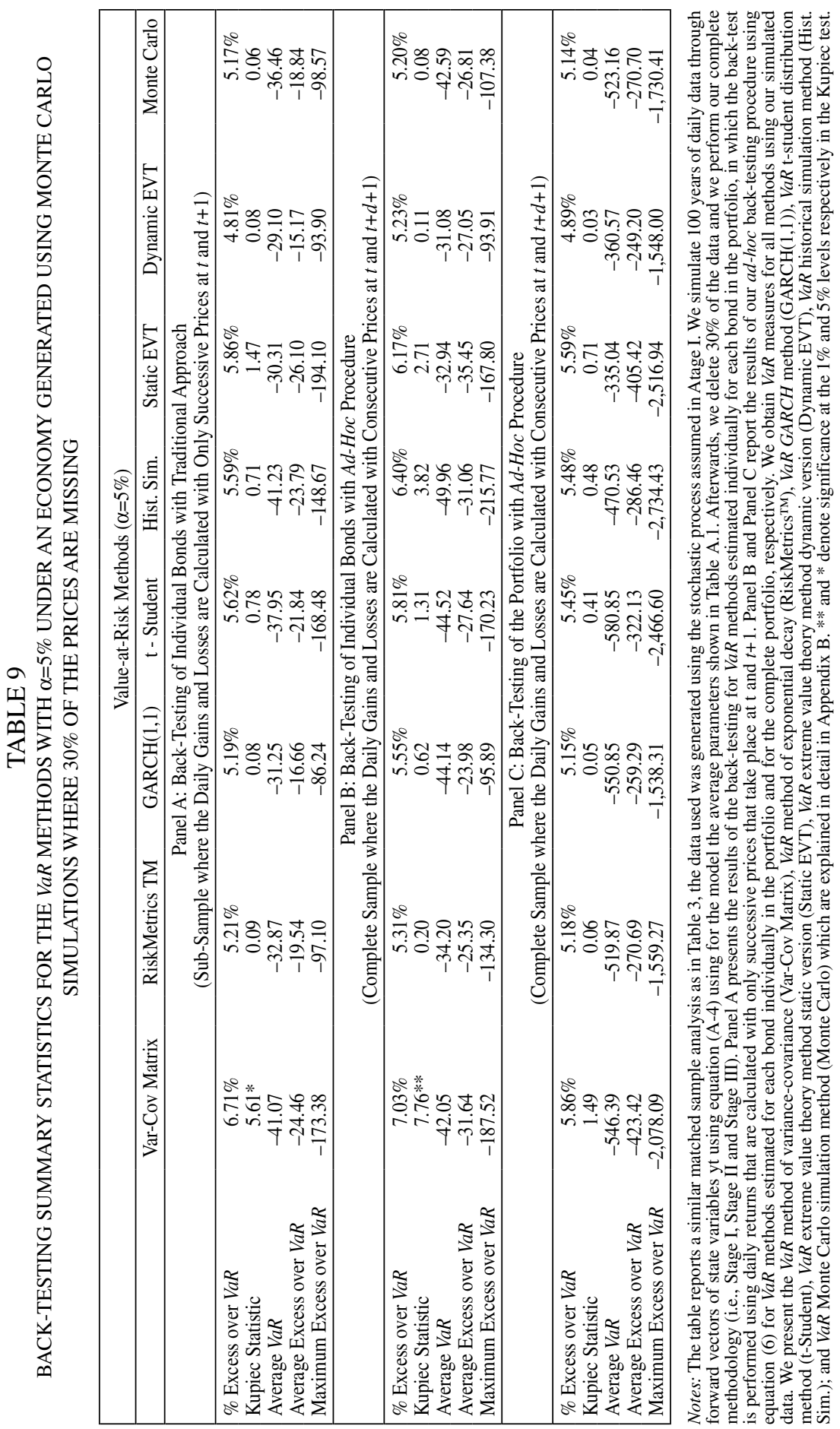


model estimated by the Kalman filter using the incomplete dataset to characterize all assets in a given portfolio and thus to obtain a complete panel data. Second, we estimate market risk measures with the new complete panel of prices. Third, we back-test the market risk measures with the observable incomplete historical panel of prices to check the reliability of our methodology. As an example of thinly traded securities, we implemented our methodology using Chilean governmental bonds traded at the Santiago Stock Exchange. Nevertheless, our approach can be applied to other markets where infrequent trading is present.

Our methodology to calculate market risks in an environment of thin trading is intuitive and flexible. We provide empirical evidence supporting that our approach provides reliable VaR measures for infrequently traded securities. Our approach outperformed the common practice of replicating the last traded price in order to calculate $\mathrm{VaR}$ measures. In addition, we showed that our methodology was robust when varying the rolling window used to estimate the term-structure model and when applied to simulated markets with different rates of non-trading days. Nevertheless, there are other important and interesting issues that we would like to investigate in the future. For example, the estimation of a complete portfolio management strategy with thinly traded assets including market risk measures together with asset allocation methods are beyond the scope of this paper. In addition, possible studies including other measures of market risk, implementations in other markets, and the use of diverse securities are left for future research. Finally, we hope that our study encourages further research in thinly traded assets across different areas of portfolio management.

\section{REFERENCES}

Antonios, A., Erguí N. and Colmes, P. (2002), "Market Efficiency, Thin Trading and Non-linear Behaviour: Evidence from an Emerging Market", European Financial Management 3, 175-190.

Babbs, S.H. and Nowman, K.B. (1999), "Kalman Filtering of Generalized Vasicek Term Structure Models", Journal of Financial and Quantitative Analysis 34, 115-130.

Bao, Y., Lee, T.H. and Saltoglu, B. (2006), "Evaluating Predictive Performance of Value-at-Risk Models in Emerging Markets: A Reality Check", Journal of Forecasting 25, 101-128.

Bartholdy, J. and Riding, A., 1994, Thin Trading and the Estimation of Betas: The Efficacy of Alternative Techniques, Journal of Financial Research 17, 241-254.

Basel Committee on Banking Supervision (1996), "Amendment to the Capital Accord to Incorporate Market Risks", Bank for International Settlements.

Basel Committee on Banking Supervision (1996), "Supervisory Framework for the Use of Backtesting in Conjunction with the Internal Models", Bank for International Settlements.

Bassett, G.W., France, V.G. and Pliska, S.R. (1991), "Kalman filter Estimation for Valuing Nontrading Securities, with Applications to the MMI CashFuture Spread on October 19 and 20, 1987', Review of Quantitative Finance and Accounting 1, 135-151. 
Bedendo, M. and Hodges, S.D. (2009), "The Dynamics of the Volatility Skew: A Kalman Filter Approach", Journal of Banking and Finance 33, 1156-1165.

Beder, T. (1995), "VAR: Seductive but Dangerous", Financial Analysts Journal $51,1224$.

Berkowitz, J. and O'Brien, J. (2002), "How Accurate are Value-at-Risk Models at Commercial Banks?", Journal of Finance 57, 1093-1112.

Black, F. Scholes, M. (1973), "The pricing of options and corporate liabilities", Journal of Political Economy, 81, 637-654.

Boabang, F. (1996), "An Adjustment Procedure for Predicting Betas When Thin Trading is Present: Canadian Evidence", Journal of Business Finance and Accounting 23, 1323-1356.

Bollerslev, T. (1986), "Generalized Autoregressive Conditional Heteroskedasticity", Journal of Econometrics 31, 307-327.

Brennan, M., Wang, A.W. and Xia, Y. (2005), "Estimation and Test of a Simple Model of Intertemporal Capital Asset Pricing", Journal of Finance 59, 1743-1776.

Britten-Jones, M. and Schaefer, S. (1999), “Nonlinear Value at Risk”, European Finance Review 2, 161-187.

Chan, K., Chung, Y.P. and Fong, W.M. (2002), "The Informational Role of Stock and Option Volume", Review of Financial Studies 15, 1049-1075.

Chen, L., Lesmond, D.A. and Wei, J. (2007), "Corporate yield spreads and bond liquidity", Journal of Finance 62, $\mathrm{N}^{\mathrm{o}} 1,119-149$.

Chen, R.R. and Scott, L. (2003), "Multi-factor Cox-Ingersoll-Ross Models of the Term Structure: Estimates and Tests from a Kalman Filter Model", Journal of Real Estate Finance and Economics 27, 143-172.

Chernobai, A., Menn, C., Rachev, S.T., Truck, S. and Moscadelli, M. (2006), "Treatment of Incomplete Data in the Field of Operational Risk: The Effects on Parameter Estimates, EL and UL Figures, in E. Davis (ed.)", The Advanced Measurement Approach to Operational Risk, Risk Books, London.

Christoffersen, P. (2003), "Elements of Financial Risk Management", Academic Press, New York.

Coles, S. (2001), "An Introduction to Statistical Modeling of Extreme Values", London, Springer-Verlag.

Cortazar, G. and Naranjo, L. (2006), "An N-factor Gaussian Model of Oil Futures", Journal of Futures Markets Vol. 26, 243-268.

Cortazar, G., Schwartz, E.S. and Naranjo, L. (2007), "Term Structure Estimation in Markets with Infrequent Trading", International Journal of Finance \& Economics Vol. 12, 353-369.

Cortazar, G., Milla, C. and Severino, F. (2008), "A Multicommodity Model of Futures Prices: Using Futures Prices of One Commodity to Estimate the Stochastic Process of Another", Journal of Futures Markets Vol. 28, 537-560.

Cortazar, G., Schwartz, E.S. and Tapia, C. (2012), "Credit Spreads in Illiquid Markets: Model and Implementation", Emerging Markets Finance and Trade Vol. 48, 53-72.

Cox J.C., Ingersoll, J. and Ross, S. (1985), "A Theory of the Term Structure of Interest Rates", Econometrica 53, 385-407. 
Davis, M.A. (1982), "Linear Estimation and Stochastic Control”, Academic Press, New York.

Duffie, D. and Kan, R. (1986), "A Yield-Factor Model of Interest Rates", Mathematical Finance 6, 379-406.

Duffie, D. and Pan, J. (1997), “An Overview of Value at Risk", Journal of Derivatives 4, 7-49.

Embrechts, P., Klüppelberg, C. and Mikosch, T. (1997), "Modelling Extremal Events for Insurance and Finance", Springer, New York.

Fernandes, J., Hasman, A. and Peña, J. (2008), "Risk Premium: Insights Over the Threshold", Applied Financial Economics 18, 41-59.

Fernández, V. (2003), "Extreme Value Theory and Value at Risk", Revista de Analisis Economico 18, 57-85.

Goncalves, S. and Guidolin, M. (2006), "Predictable dynamics in the S\&P 500 index options implied volatility surface", Journal of Business 79, 1591-1636.

Geyer, A.L. and Pichler, S. (1999), “A State-Space Approach to Estimate and Test Multifactor Cox-Ingersoll-Ross Models of the Term Structure", Journal of Financial Research 22, 107-130.

Guidolin, M. and Timmermann, A. (2006), "Term Structure of Risk under Alternative Econometric Specifications”, Journal of Econometrics 131, 285-308.

Harvey, A.C. (1982), "The Kalman Filter and Its Applications in Econometrics and Time Series Analysis", Methods of Operations Research 44, 3-18.

He, Z., Huh, S.W. and Lee, B.S. (2010), "Dynamic Factors and Asset Pricing", Journal of Financial and Quantitative Analysis 45, 707-737.

Hyung, N. and de Vries, C.G. (2007), "Portfolio selection with heavy tails, Tinbergen Institute Discussion", Journal of Empirical Finance 14, № 3, 383-400

Jackson, P., Maude, D.J. and Perraudin, W. (1997), "Bank Capital and Value at Risk", Journal of Derivatives 4, 73-90.

Jokivuolle, E. (1995), "Measuring True Stock Index Value in the Presence of Infrequent Trading", Journal of Financial and Quantitative Analysis 30, 455-464.

Jorion, P. (2006), "Value at Risk: The Benchmark for Managing Financial Risk", McGraw Hill, New York.

Kallunki, J. (1997), "Handling Missing Prices in a Thinly Traded Stock Market: Implications for the Specification of Event Study Methods", European Journal of Operational Research 103, 186-197.

Kawata, R. and Kijima, M. (2007), "Value-at-Risk in a Market Subject to Regime Switching”, Quantitative Finance 7, 609-619.

Kiesel, R., Perraudin, W. and Taylor, A., 2000, An Extreme Analysis of VaRs for Emerging Market Benchmark Bonds, Working Paper, University of London - Birkbeck College.

Kuester, K., Mittnik, S. and Paolella, M.S. (2006), "Value-at-Risk Prediction: A Comparison of Alternative Strategies", Journal of Financial Econometrics 4, 53-89.

Kupiec, P. (1995), “Techniques for Verifying the Accuracy of Risk Measurement Models", Journal of Derivatives 3, 73-84. 
Lim, K.P., Habibullah, M.S. and Hinich, M.J. (2009), “The Weak-Form Efficiency of Chinese Stock Markets: Thin Trading, Nonlinearity and Episodic Serial Dependencies", Journal of Emerging Market Finance 8, 133-163. Longerstaey, J. and Spencer, M. (1996), RiskMetrics ${ }^{\text {TM}}-$ Technical Document, J.P. Morgan, New York.

Lucas, A. (2000), "A Note on Optimal Estimation from a Risk-Management Perspective under Possibly Misspecified Tail Behavior", Journal of Business \& Economic Statistics 18, 31-39.

Manganelli, S. and Engle, R. (2001), "Value at Risk Models in Finance", Working Paper, European Central Bank.

Martikainen, T., Perttunen, J., Yli-Olli, P. and Gunasekaran, A. (1996), “On the Impact of Infrequent Trading on the APT Systematic Risk Components: Evidence from a Thin Security Market", European Journal of Operational Research 88, 23-27.

Mayhew, S. and Mihov, V. (2004), "How do Exchanges Select Stocks for Option Listing?", Journal of Finance 59, 447-471.

McCulloch, J.H. (1971), "Measuring the Term Structure of Interest Rates", Journal of Business 44, 19-31.

McNeil, A. and Frey, R. (2000), "Estimation of Tail-Related Risk Measures for Heteroscedastic Financial Times Series: An Extreme Value Approach", Journal of Empirical Finance 7, 271-300.

Miller, M.H., Muthuswamy, J., and Whaley, R.E. (1994), "Mean Reversion of Standard \& Poor's 500 Index Basis Changes: Arbitrage-Induced or Statistical Illusion?", Journal of Finance 49, 479-513.

Moscadelli, M., Chernobai, A. and Rachev, S.T. (2005), “Treatment of Incomplete Data in the Field of Operational Risk: the Effects on Parameter Estimates, EL, and UL figures", Operational Risk 6, 28-34.

Nelson, C.R. and Siegel, A.F. (1987), "Parsimonious Modeling of Yield Curves", Journal of Business 60, 473-489.

Pérignona, C. and Smith, D.R. (2010), "The Level and Quality of Value-at-Risk Disclosure by Commercial Banks", Journal of Banking and Finance 34, 362-377.

Pritsker, M. (2006), “The Hidden Dangers of Historical Simulation”, Journal of Banking and Finance 30, 561-582.

Rockafellar, R.T. and Uryasev, S. (2000), "Optimization of Conditional Valueat-Risk", Journal of Risk 2, 21-41.

Rockafellar, R.T. and Uryasev, S. (2002), "Conditional Value-at-Risk for General Loss Distributions", Journal of Banking and Finance 26, 1443-1471.

Roll, R., Schwartz, E. and Subrahmanyam, A. (2007), "Liquidity and the Law of one Price: the Case of the Futures-Cash Basis", Journal of Finance 62, 2201-2234.

Ruiz, E. (1994), “Quasi-Maximum Likelihood Estimation of Stochastic Volatility Models", Journal of Econometrics 63, 289-306.

Sercu, P., Vandebroek, M. and Vinaimont, T. (2008), "Thin-Trading Effects in Beta: Bias v. Estimation Error", Journal of Business Finance and Accounting 35, 1196-1219.

Simon, D. (2006), “Optimal State Estimation: Kalman, H-Infinity, and Nonlinear Approaches", Wiley \& Sons, New Jersey. 
Singh, M. (1997), "Value at Risk Using Principal Components Analysis", Journal of Portfolio Management 24, 101112.

Svensson, L.E.O. (1994), "Estimating and Interpreting Forward Interest Rates: Sweden 1992-1994", Working Paper, NBER.

Vasicek, A. (1977), "An Equilibrium Characterization of the Term Structure", Journal of Financial Economics 5, 177-188.

Vasicek A., Fong, H.G. (1982), "Term Structure Modeling Using Exponential Splines", Journal of Finance 37, 339-356.

Wilson, T. (1993), "Infinite Wisdom", Risk 6, 37-46.

Wooldridge, J.M. (1991), "Specification Testing and Quasi-Maximum-Likelihood Estimation", Journal of Econometrics 48, 29-55. 


\section{Appendix A: The Dynamic Term-Structure Model ANd its Estimation}

In the three-factor generalized Vasicek model, three stochastic unobservable mean-reverting state variables are defined and represented by the $3 \times 1$ vector $\mathbf{y}_{\mathbf{t}}$. Then, the instantaneous interest rate, $q_{t}$, may be defined as:

$$
q_{t}=\mathbf{1}^{\prime} \mathbf{y}_{t}+\delta
$$

where $\delta$ is a constant. In addition, the vector of state variables follows a multifactor Vasicek-type process governed by the stochastic differential equation:

$$
d \mathbf{y}_{t}=-\mathbf{K y}_{t} d t+\Sigma d \mathbf{w}_{t},
$$

in which $\mathbf{K}=\operatorname{diag}\left(\kappa_{i}\right)$ and $\Sigma=\operatorname{diag}\left(\sigma_{i}\right)$ are $3 \times 3$ diagonal matrices with $i$ representing the respective state variables; and $d \mathbf{w}_{t}$ is a $3 \times 1$ vector of correlated Brownian motion processes such that:

$$
\left(d \mathbf{w}_{t}\right)\left(d \mathbf{w}_{t}\right)^{\prime}=\mathbf{\Omega} d t
$$

Here, $\rho_{i, j}$ is one of the elements of $\mathbf{\Omega}$ which represents the instantaneous correlation between the state variables $i$ and $j$. Under this specification, the state variables have a multivariate normal distribution, and each of them reverts to zero with a mean reversion rate given by $\kappa_{i}$. Thus, from equation $(\mathrm{A}-1)$ the instantaneous interest rate, $q_{t}$, reverts to a long-run mean given by the constant $\delta$. By assuming a constant $3 \times 1$ vector of risk premiums, $\lambda$, the risk adjusted process of the state variables can be expressed as:

$$
d \mathbf{y}_{t}=-\left(\lambda+\mathbf{K} \mathbf{y}_{t}\right) d t+\Sigma d \mathbf{w}_{t} .
$$

Additionally, through standard no-arbitrage arguments we can obtain the price of any pure-discount bond with maturity $\tau$ as:

$$
P\left(\mathbf{y}_{t}, \tau\right)=\exp \left(\mathbf{u}(\tau)^{\prime} \mathbf{y}_{t}+v(\tau)\right)
$$

where

$$
u_{i}(\tau)=-\frac{1-\exp \left(-k_{i} \tau\right)}{k_{i}}
$$

and

$$
\begin{aligned}
& v(\tau)=\sum_{i=1}^{N} \frac{\lambda_{i}}{k_{i}}\left(\tau-\frac{1-\exp \left(-k_{i} \tau\right.}{k_{i}}\right)-\delta \cdot \tau \\
& +\frac{1}{2} \sum_{i=1}^{N} \sum_{j=1}^{N} \frac{\sigma_{i} \sigma_{j} \rho_{i j}}{k_{i} k_{j}}\left(\tau-\frac{1-\exp \left(-k_{i} \tau\right)}{k_{i}}-\frac{1-\exp \left(-k_{j} \tau\right)}{k_{j}}+\frac{1-\exp \left(-\left(k_{i}+k\right) \tau\right.}{k_{i}+k_{j}}\right.
\end{aligned}
$$


In addition, the equivalent annualized spot rate, $Q\left(\mathbf{y}_{t}, \tau\right)$, is:

$$
Q\left(\mathbf{y}_{t}, \tau\right)=-\frac{1}{\tau}\left(\mathbf{u}(\tau)^{\prime} \mathbf{y}_{t}+v(\tau)\right)
$$

which is a linear function of the state variables. Therefore, under the generalized Vasicek model spot rates also follow a Gaussian distribution. Afterwards, we estimate this model by the Kalman filter, in which the unobservable state variables contained in vector $\mathbf{y}_{\mathrm{t}}$ are calculated recursively using all the information available until time $t$. In the state-space representation, the measurement equation that relates the vector of observable variables $\mathbf{b}_{t}$ with the vector of unobservable state variables $\mathbf{y}_{t}$, is:

$$
\mathbf{b}_{t}=\mathbf{H}_{t} \mathbf{y}_{t}+\mathbf{d}_{t}+\mathbf{v}_{t}, \quad \mathbf{v}_{t} \sim N\left(0, \Gamma_{t}\right) .
$$

We must recall that the standard Kalman filter assumes a fixed number of observable variables at each time. However, this assumption can be relaxed in order to allow for missing observations. Let $m_{t}$ be the number of observations available at time $t$, then $\mathbf{b}_{t}$ is an $m_{t} \times 1$ vector, $\mathbf{H}_{t}$ is an $m_{t} \times 3$ matrix, $\mathbf{d}_{t}$ is an $m_{t} \times 1$ vector, and $\mathbf{v}_{t}$ is an $m_{t} \times 1$ vector of serially uncorrelated Gaussian disturbances with mean zero and covariance matrix $\Gamma_{t}$ with dimensions $m_{t} \times m_{t}$. The transition equation, which describes the dynamics of the state variables, may be written as:

$$
\mathbf{y}_{t}=\mathbf{A}_{t} \mathbf{y}_{t-1}+\mathbf{c}_{t}+\varepsilon_{t}, \quad \varepsilon_{t} \sim N\left(0, \mathbf{D}_{t}\right),
$$

where $\mathbf{A}_{\mathrm{t}}$ is a $3 \times 3$ matrix, $\mathbf{c}_{\mathrm{t}}$ is a $3 \mathrm{x} 1$ vector, and $\varepsilon_{\mathrm{t}}$ is a $3 \times 1$ vector of uncorrelated Gaussian noise with mean zero and covariance matrix $\mathbf{D}_{t} \cdot{ }^{24}$ In the iterative estimation process of the Kalman filter, estimates of the state variables, $\hat{\mathbf{y}}_{t}$, are obtained recursively where $\mathbf{J}_{t}$ is the covariance matrix of the estimation errors:

$$
\mathbf{J}_{t}=E\left(\mathbf{y}_{t}-\hat{\mathbf{y}}_{t}\right)\left(\mathbf{y}_{t}-\hat{\mathbf{y}}_{t}\right)^{\prime}
$$

Consequently, in the iterative process given all the information at $t$ - 1 , estimates of the state variables and the covariance matrix of the estimation errors at $t$ can be written as:

$$
\hat{\mathbf{y}}_{t \mid t-1}=\mathbf{A}_{t} \hat{\mathbf{y}}_{t-1}+\mathbf{c}_{t},
$$

$$
\mathbf{J}_{t \mid t-1}=\mathbf{A}_{t} \mathbf{J}_{t-1} \mathbf{A}_{t}^{\prime}+\mathbf{D}_{t}
$$

24 It is important to mention that the Kalman filter needs that at least one security is traded; this issue is not a big constraint since the inexistence of at least one transaction is very unlikely (e.g. in our sample we have all days with at least one transaction in the portfolio of 20 bonds). However, in the improbable case of a day with zero transactions it is possible to use the middle points of the bid-ask spreads of the most liquid securities as the prices in the model. 
Equations (A-12) and (A-13) are known as the prediction steps. In addition when new information arrives at $t$ through the observable variables $\left(\mathbf{b}_{t}\right)$, we can obtain unconditional estimates of the state variables and the covariance matrix of the estimation errors as follows:

$$
\begin{gathered}
\hat{\mathbf{y}}_{t}=\hat{\mathbf{y}}_{t \mid t-1}+\mathbf{J}_{t \mid t-1} \mathbf{H}_{t}^{\prime} \mathbf{F}_{t}^{-1}\left(\mathbf{b}_{t}-\mathbf{H}_{t} \hat{\mathbf{y}}_{t \mid t-1}-\mathbf{d}_{t}\right), \\
\mathbf{J}_{t}=\mathbf{J}_{t \mid t-1}-\mathbf{J}_{t \mid t-1} \mathbf{H}_{t}^{\prime} \mathbf{F}_{t}^{-1} \mathbf{H}_{t} \mathbf{J}_{t \mid t-1},
\end{gathered}
$$

where

$$
\mathbf{F}_{t}=\mathbf{H}_{t} \mathbf{J}_{t \mid t-1} \mathbf{H}_{t}^{\prime}+\Gamma_{t} .
$$

As a final step, the unknown model parameters represented by the vector $\varphi$ can be estimated by maximizing the log-likelihood function of the error innovations given by:

$$
\text { (A-17) } \log L(\varphi)=-\frac{1}{2} \sum_{t} \log \left|\mathbf{F}_{t}\right|-\frac{1}{2} \sum_{t}\left(\mathbf{b}_{t}-\mathbf{H}_{t} \hat{\mathbf{y}}_{t \mid t-1}-\mathbf{d}_{t}\right)^{\prime} \mathbf{F}_{t}^{-1}\left(\mathbf{b}_{t}-\mathbf{H}_{t} \hat{\mathbf{y}}_{t \mid t-1}-\mathbf{d}_{t}\right) \text {. }
$$

We estimate the model using a six-month daily rolling window. Therefore, we obtain a complete data panel from July 1999 because the first 6 months are necessary for the first estimation. Table A.1 presents the averages of the mean value, the standard deviation, and the mean of standard errors of parameter estimates for the three-factor generalized Vasicek term-structure dynamic model defined previously. The table shows average statistics of the daily mean reversion parameters $\left(\kappa_{1}, \kappa_{2}, \kappa_{3}\right)$; the volatility parameters $\left(\sigma_{1}, \sigma_{2}, \sigma_{3}\right)$; the correlation coefficients of the state variables $\left(\rho_{12}, \rho_{13}, \rho_{23}\right)$ the long-run mean of interest rates $\delta$; the market prices of risk $\left(\lambda_{1}, \lambda_{2}, \lambda_{3}\right)$; and the state variables contained in y_t. Even though, Vasicek's (1977) dynamic model assumes a constant volatility of the spot interest rate and thus the volatility parameters should be constant; the volatility parameters change over time which is reflected in their standard deviations. The parameters of the model are not constant due to the fact that we estimate each day this multifactor dynamic term-structure model (and hence the spot volatility of the interest rate can also change over time), which gives flexibility to our model to capture market movements that are fundamental for risk management. In addition, it is important to observe that on average the $\kappa_{1}$ parameter estimate is nearly zero; this indicates that the first factor is nearly a random walk and it explains why our estimate of $\lambda_{1}$ is close to zero. ${ }^{25}$

25 Notice that we could have imposed a random walk factor. However, we allowed flexibility to the model as other trading environments might not have shown the behavior found in our empirical application. 
TABLE A.1

SUMMARY STATISTICS OF THE DAILY AVERAGES OF THE PARAMETERS ESTIMATED AND STATE VARIABLES OF THE DYNAMIC

TERM-STRUCTURE MODEL OF INTEREST RATES

\begin{tabular}{|cccc|}
\hline Parameters & Mean Parameter & Stand. Dev. Parameters & Mean Stand. Errors \\
\hline$\kappa_{1}$ & 0.019 & $4.51 \mathrm{E}-3$ & $1.58 \mathrm{E}-4$ \\
$\kappa_{2}$ & 0.942 & $1.71 \mathrm{E}-2$ & $1.91 \mathrm{E}-2$ \\
$\kappa_{3}$ & 1.964 & $5.37 \mathrm{E}-2$ & $6.39 \mathrm{E}-2$ \\
$\sigma_{1}$ & 0.017 & $2.30 \mathrm{E}-4$ & $2.17 \mathrm{E}-4$ \\
$\sigma_{2}$ & 0.175 & $2.79 \mathrm{E}-3$ & $5.35 \mathrm{E}-3$ \\
$\sigma_{3}$ & 0.196 & $3.92 \mathrm{E}-3$ & $6.18 \mathrm{E}-3$ \\
$\rho_{12}$ & -0.699 & $1.09 \mathrm{E}-2$ & $1.57 \mathrm{E}-2$ \\
$\rho_{13}$ & 0.388 & $9.76 \mathrm{E}-3$ & $8.37 \mathrm{E}-3$ \\
$\rho_{23}$ & -0.826 & $2.12 \mathrm{E}-3$ & $4.84 \mathrm{E}-3$ \\
$\delta$ & 0.051 & $4.11 \mathrm{E}-2$ & $3.73 \mathrm{E}-2$ \\
$\lambda_{1}$ & 0.000 & $1.07 \mathrm{E}-5$ & $3.74 \mathrm{E}-5$ \\
$\lambda_{2}$ & -0.016 & $3.75 \mathrm{E}-3$ & $5.80 \mathrm{E}-3$ \\
$\lambda_{3}$ & -0.023 & $8.38 \mathrm{E}-3$ & $1.97 \mathrm{E}-2$ \\
$\psi_{1}$ & -0.052 & $6.87 \mathrm{E}-3$ & $5.78 \mathrm{E}-3$ \\
$\psi_{2}$ & -0.005 & $6.90 \mathrm{E}-2$ & $2.92 \mathrm{E}-2$ \\
$\psi_{3}$ & 0.016 & $7.83 \mathrm{E}-2$ & $4.68 \mathrm{E}-2$ \\
\hline
\end{tabular}




\section{Appendix B: Analysis of Prices and Returns between fair and MARKET DATA}

In this Appendix we present relationships between fair and market prices and between fair and market returns. These analyses are useful to understand how we should generate complete data panels of historical prices. For instance, in the case that fair prices and fair returns are very close to market data, then both panels could be merged where fair prices are used when market transactions are not available; and thus later to obtain a complete dataset of asset returns. However, in the case that fair prices are biased in relation to the prices observed in the market, but fair returns are not (as we will show in this Appendix), then it is better to make use of only fair prices to calculate the returns instead of a mixed dataset.

Table B.1 Panel A provides summary statistics of measurement errors between fair and market prices for the complete sample of 20 bonds. In addition, Table B.1 Panel B reports summary statistics for errors between fair and market returns calculated with only successive prices (i.e. o $t$ and $t+1$ ). In Table B.1, we report the mean of errors, the standard deviation of errors, t-statistics, the mean of the absolute value of errors $(M A E)$, and the root mean of the squared errors (RMSE). Table B.1 Panel A show biases between fair and market prices; in which practically all bonds have the mean of the errors between fair and market prices significantly different from zero. The reason is that the dynamic term-structure of the interest rates model on average replicates the behavior of option prices. However, fair prices for liquid bonds (see Table 1), such as bonds with maturities of $07 ; 08 ; 19$ and 20 years, are consistently underestimated by the model. By contrast, illiquid bonds are overestimated. Therefore, biases are due to the differences of liquidity premiums among bonds. Nevertheless, Table B.1 Panel B shows that fair returns are not statistically different from the observed market returns. Table B.1 Panel B suggests that, even though fair prices are biased, the movements or changes of the complete market term-structure of the interest rates are well represented by the movements of the fair term-structure of the interest rates estimated through the three-factor dynamic term-structure model. This is mainly due to the fact that we estimate on a daily basis the multifactor term-structure model of the interest rates, which allow us to capture the movements of the interest rates over time. Thus, the evidence suggests that:

$$
\ln \left(\frac{P_{t+1}}{P_{t}}\right) \approx \ln \left(\frac{\hat{P}_{t+1}}{\hat{P}_{t}}\right),
$$

where $\hat{P}_{t}$ and $\hat{P}_{t+1}$ are fair prices. We repeat the same analysis reported in Table A.1 but using two sub-samples in Table B.2 and Table B.3. Table B.2 and Table B. 3 shows the consistency of the results of Table B.1. Consequently, in our implementation we assume that fair returns replicate very closely market returns. This assumption is very important, given that it is a necessary condition to obtain reliable $\mathrm{VaR}$ measures and is also useful for the $a d-h o c$ back-testing procedure. 


\begin{tabular}{|c|c|c|c|c|c|c|}
\hline 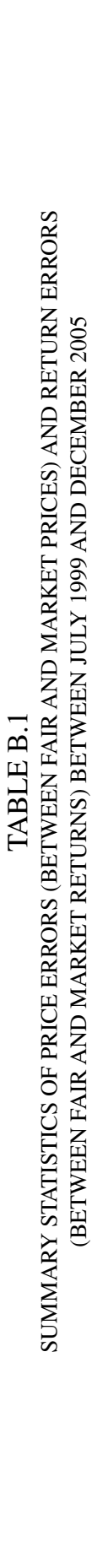 & 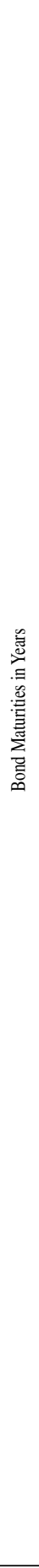 & $\begin{array}{l}\infty \\
- \\
0 \\
\infty \\
+ \\
\infty \\
+\end{array}$ & 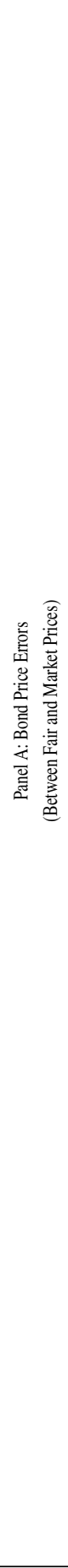 & 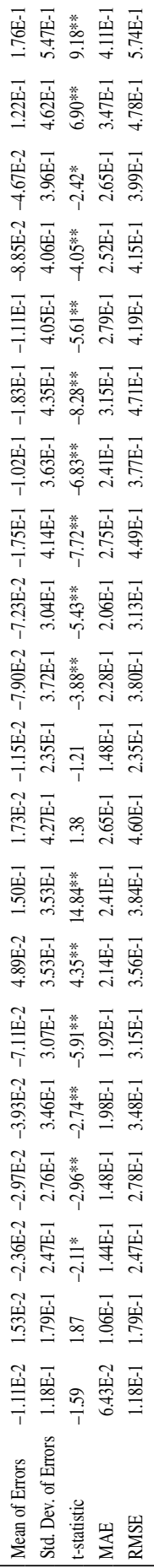 & 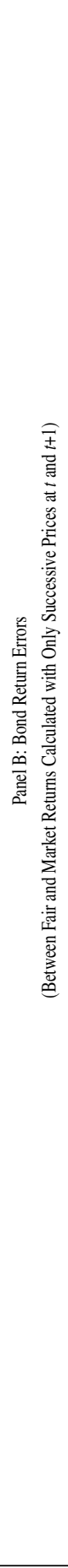 & 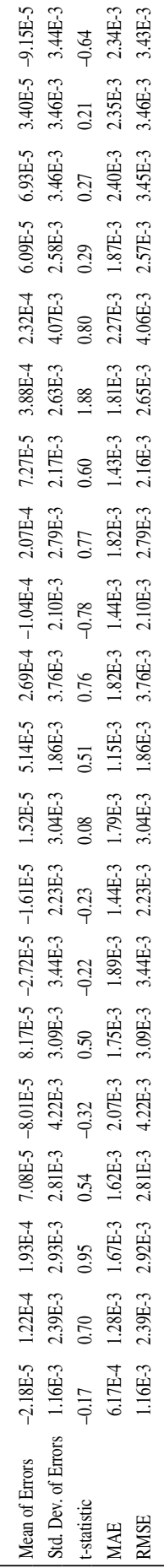 \\
\hline
\end{tabular}




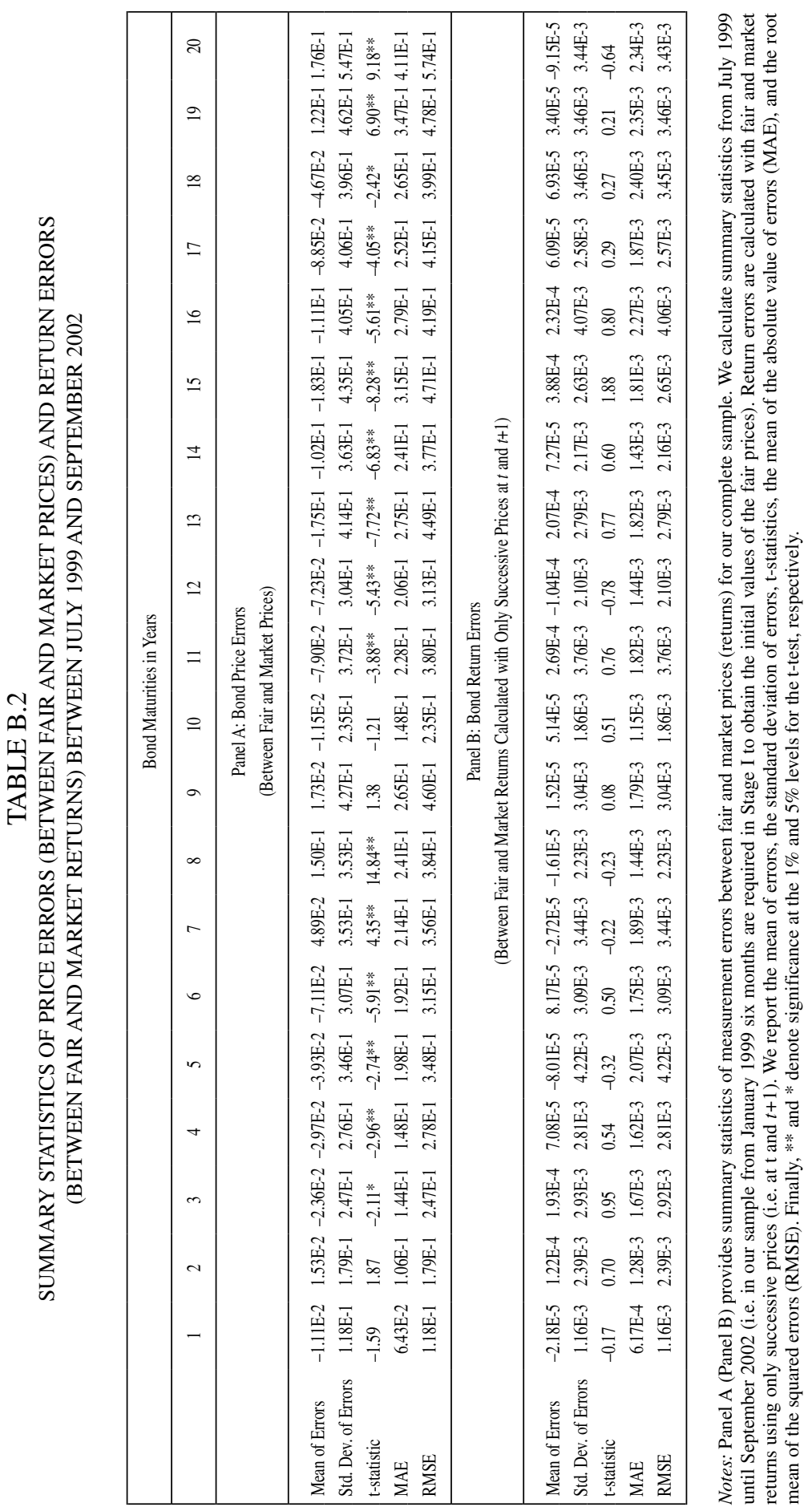




\begin{tabular}{|c|c|c|c|c|c|c|}
\hline 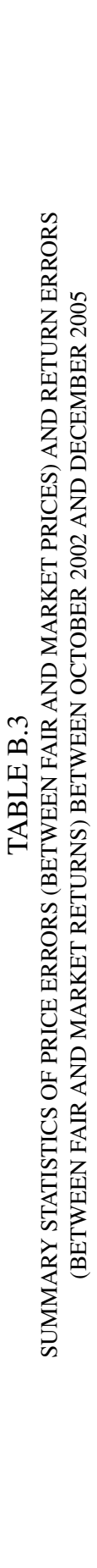 & 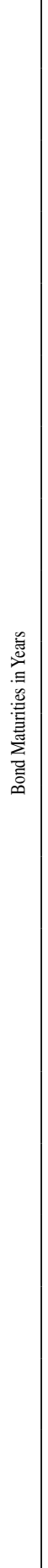 & $\begin{array}{l}- \\
0 \\
\text { in }\end{array}$ & 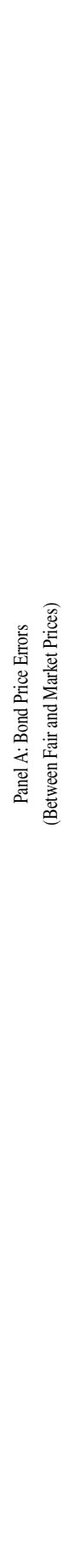 & 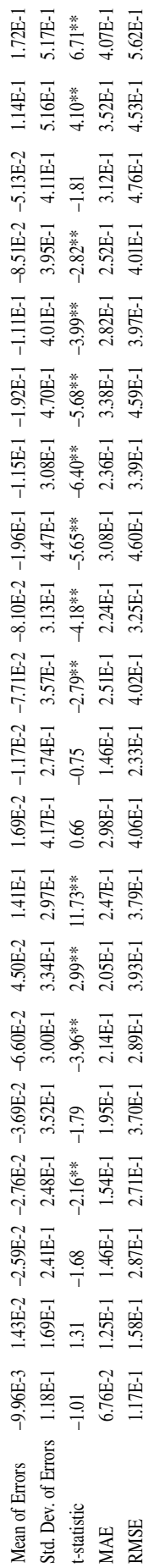 & 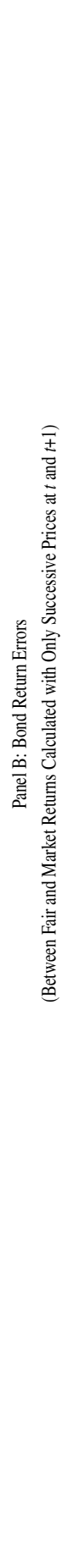 & 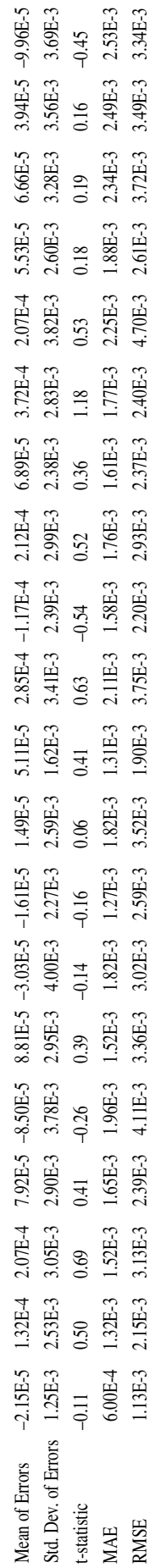 \\
\hline
\end{tabular}




\section{Appendix C: Value at Risk Measures}

\section{Parametric Methods Using Multivariate Normal Distributions}

\section{The VaR method of variance-covariance}

The method of variance-covariance assumes a multivariate normal distribution of the log returns, in which the variance-covariance matrix is calculated with the historical returns. In the case of a single asset, the VaR with an $\alpha$ confidence level is:

$$
V a R_{t, t+1}=\left(e^{\left(u+\frac{\sigma^{2}}{2}\right)+\sigma \psi}-1\right) M,
$$

where $u$ and $\sigma^{2}$ are the mean and variance of log-returns, $\psi$ is the inverse of a $N(0,1)$ with probability $\alpha$, and $M$ is the amount invested. In addition, equation $(\mathrm{C}-1)$ is also used for the $V a R$ of the portfolio, but the portfolio variance is obtained using the variance-covariance matrix (i.e. $\sigma^{2}=\omega^{\prime} \Theta \omega$, where $\omega$ is the vector of weights for the different assets of the portfolio, and $\Theta$ is the variancecovariance matrix). In our implementation we use a rolling window of 252 days for the estimations.

The VaR method of exponential decay (using the RiskMetrics ${ }^{\mathrm{TM}}$ version)

This method, which was popularized by J.P. Morgan in the nineties, is characterized by its simplicity (see Longerstaey and Spencer, 1996), where the elements in the variance-covariance matrix are calculated using:

$$
\sigma_{i, j, t}^{2}=\lambda_{R M} \cdot \sigma_{i, j, t-1}^{2}+\left(1-\lambda_{R M}\right) \cdot r_{i, t-1} r_{j, t-1},
$$

here $r_{i, t}$ is the $\log$ return for the asset $i$ on dat $t ; \sigma_{i, j, t}$ the covariance between the assets $i$ and $j$; and $\lambda_{R M}=0.94$. Therefore, the $V a R$ can be calculated using equation $(\mathrm{C}-1)$ for a single asset but the return volatility is estimated by equation (C-2). For a portfolio, the $\mathrm{VaR}$ is also calculated using equation $(\mathrm{C}-1)$ with a variance covariance matrix equal to $\sigma^{2}=\omega^{\prime} \Theta \omega$, where the elements of $\Theta$ are obtained by equation (C-2). We also use a rolling window of 252 days for the estimations with this method.

The VaR GARCH(1,1) method

Following Bollerslev (1986), we use:

$$
r_{i, t}=u+\sigma_{t} \cdot z_{t}
$$

$$
\varepsilon_{t}=\sigma_{t} \cdot z_{t},
$$




$$
\sigma_{t}^{2}=\eta_{0}+\eta_{1} \cdot \varepsilon_{t-1}^{2}+\eta_{2} \cdot \sigma_{t-1}^{2}
$$

where $z_{t}$ are iid innovations with zero mean and unit variance. Once we have estimated the $G A R C H(1,1)$ model, we obtain estimates for $\sigma_{t}$ and the $V a R$ for a single asset is calculated using equation $(\mathrm{C}-1)$. The $\mathrm{VaR}$ for the complete portfolio is calculated using the $\operatorname{GARCH}(1,1)$ model for the daily portfolio returns:

$$
r_{\text {portf }, t}=\sum_{i=1}^{c} \omega_{i} \cdot r_{i, t}
$$

Afterwards, we also use equation (C-1) with the estimate of the portfolio volatility to obtain the VaR of the portfolio. This procedure is used instead of a multivariate GARCH model where many parameters should be estimated. The assumption that the portfolio can be taken as a single asset is due to the fact that many assets in the economy are themselves portfolios. Moreover, in our implementation each bond is a portfolio composed by different cash flows or coupons (zero coupon bonds). As with the previous VaR methods we use a rolling window of 252 days for the estimations.

\section{Parametric Methods Taking into Account Asymmetries and Kurtosis of Returns}

\section{The VaR t-student distribution method}

We used a t-student distribution for the security returns to calculate the VaR following the work of Wilson (1993) and Lucas (2000). The t-student distribution has the advantage of better adjustments to tails than normal distributions. After estimating the parameters of the t-student distribution we can use it to estimate the VaR. The VaR for the portfolio is calculated estimating the parameters for a $\mathrm{t}$-student distribution using the daily returns of the complete portfolio calculated with equation (C-6). As previous methods, we again use a rolling window of 252 days for the estimations.

\section{The VaR extreme value theory method (static version)}

The VaR methods that incorporate the extreme value theory (EVT) try to characterize just the left tail of the return distribution (see, e.g., Embrechts et al., 1997). The idea is to fit returns, which are under a threshold $\mu$, to a transformation of the Generalized Pareto Distribution $(G P D)$ :

$$
G_{\xi, \beta(\mu)}(y)=\left\{\begin{array}{ll}
1-\left(1+\frac{\xi y}{\beta}\right)^{-1 / \xi} & \xi \neq 0 \\
1-\exp \left(\frac{-y}{\beta}\right) & \xi=0
\end{array},\right.
$$


where $\xi$ and $\beta$ are the parameters of the GPD. Following McNeil and Frey (2000), we use $\mu$ values in which the number of points under the threshold represents the $10 \%$ of the data in the left tail. In addition, as Embrechts et al. (1997), Coles (2001), and McNeil and Frey (2000) we can calculate the VaR of a single asset as:

$$
V_{\alpha} R_{\alpha}^{E V T-\text { Static }}=\left[\mu+\frac{\beta}{\xi}\left(\left(\frac{n}{k_{\mu}}(1-\alpha)\right)^{-\xi}-1\right)\right] M,
$$

where $k_{\mu}$ is the number of observations in excess of the threshold $\mu$; and $n$ is the sample size used for the GPD estimation. The VaR of a portfolio is calculated using the portfolio returns by equation (C-6) and then by equation (C-8). We use a rolling window of 400 days which is larger than rolling window used in previous methods since the GPD is estimated only with returns under the threshold $\mu$, therefore we need enough data to have large investment losses in the left tail of the distribution.

\section{The VaR extreme value theory method (dynamic version)}

The static version of the EVT method (like other methods such as the VaR variance-covariance and t-student distribution methods) allocates the same weight to recent and past data, and thus it does not consider volatility heteroskedasticity. In this context, McNeil and Frey (2000) develope a dynamic EVT method for $V a R$ calculations with the purpose of taking into account quick market changes of returns. Following McNeil and Frey (2000) the dynamic EVT method for the VaR is estimated in a three-step procedure. First, we estimate the return volatilities using a $\operatorname{GARCH}(1,1)$ model by maximum likelihood assuming normal distribution of the error term. Second, we take the residuals $z_{t}$ in the $\operatorname{GARCH}(1,1)$ model using the estimated parameters from the preceding step, and we fit a GPD to those residuals represented by $G\left(z_{t}\right)$. The method proposed by McNeil and Frey (2000) assumes that in a $G A R C H(1,1)$ model, although the residuals are not distributed following a normal distribution, maximum likelihood assuming normal distribution of the residuals can be used to obtain consistent estimates (see Wooldridge, 1991; and Ruiz, 1994). Third, we estimate the value of the inverse of the GPD distribution of residuals, $\operatorname{INV}\left(G\left(z_{t}\right), \alpha\right)$, for the $\operatorname{VaR}$ with an $\alpha$ confidence level. Then $\operatorname{INV}\left(G\left(z_{t}\right), \alpha\right)$ replaces $\psi$ in equation $(\mathrm{C}-1)$, and $\sigma$ is obtained from the $\operatorname{GARCH}(1,1)$ model:

$$
V a R_{\alpha}^{\text {EVT Dynamic }}=\left(e^{\left(u+\frac{\sigma^{2}}{2}\right)+\sigma \cdot I N V\left(G\left(z_{t}\right), \alpha\right)}-1\right) M .
$$

For the VaR of the complete portfolio, we repeat the same three steps calculating the portfolio returns as a single asset using equation (C-6). We also use a rolling window of 400 days for the estimations. 


\section{Non-Parametric Methods}

\section{The VaR historical simulation method}

The most popular non-parametric approach is the historical simulation method, which is based on the histogram of the historical returns where the percentile $\alpha$ multiplied by the amount invested reflects the VaR with an $\alpha$ confidence level. In the same way as previous methods, the VaR of portfolio is estimated with the returns calculated as a single asset using equation (B-6). A rolling window of 252 days is taken for VaR estimations with this method.

\section{Monte Carlo Simulation Methods}

\section{The VaR Monte Carlo simulation method using a dynamic} stochastic process for term-structure of the interest rates

Following Beder (1995), Longerstaey and Spencer (1996), and Singh (1997), the first step in a Monte Carlo method for estimating the VaR is to specify a stochastic process that describes the financial variables of the assets in the portfolio. In our implementation, we take advantage of the process which is followed by the term-structure of the interest rates characterized in the first stage of our methodology (i.e. a dynamic three-factor model). Then, with the parameters estimated we simulate prices using the stochastic process assumed (i.e. we simulate multiple forward vectors of state variables $\mathbf{y}_{t}$ using equation (A-4)). With these simulations, we can generate a set of returns and therefore a set of investment outcomes, thus we obtain the VaR measure taking the percentile $\alpha$ of those values multiplied by the amount invested.

Finally and in relation to all methods, since some VaR methods used in our implementation require 400 historical days to be performed, we obtain VaR measures for all of them from January 2001 onwards (i.e. in our sample from January 1999 six months are required in Stage I to obtain the initial values of the fair prices, plus one year and a half of a complete panel of returns are also required to calculate the $\operatorname{VaR}$ measures). 


\section{Appendix D: Back-Testing Using Different Subsamples}

In this appendix, we report results of the back-testing for different VaR methods with $\alpha=5 \%$ ( $\alpha=1 \%$ ) in our implementation using the portfolio of Chilean bonds for two subsample in Table D.1 and Table D.2 (Table D.3 and Table D.4). We can observe in Table D.1 ad Table D.2 (Table D.3 and Table D.4) that results of the back-testing procedure are stables over time; and thus confirming the consistency of the results showed for the complete sample in Table 3 (Table 4). 


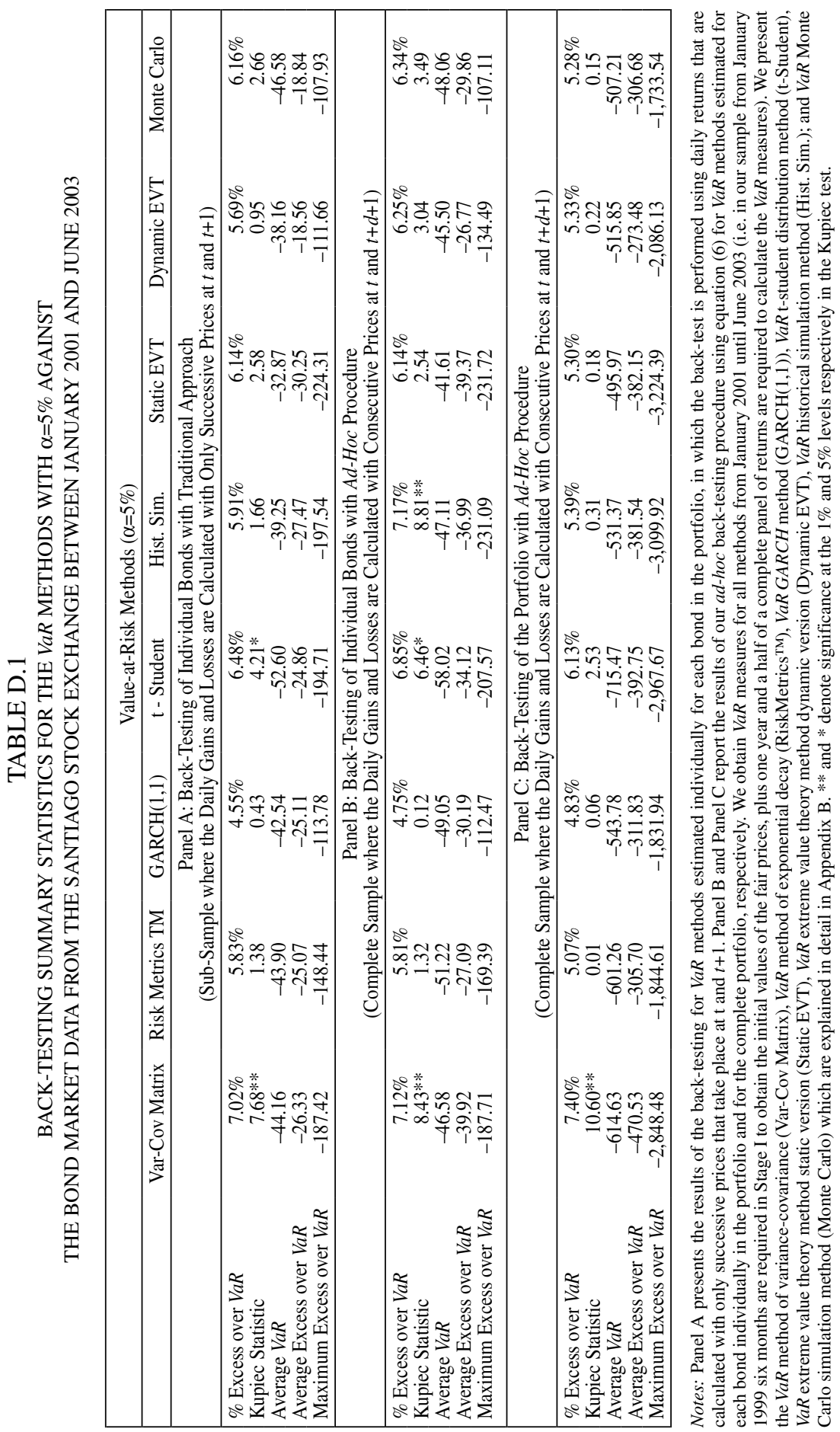




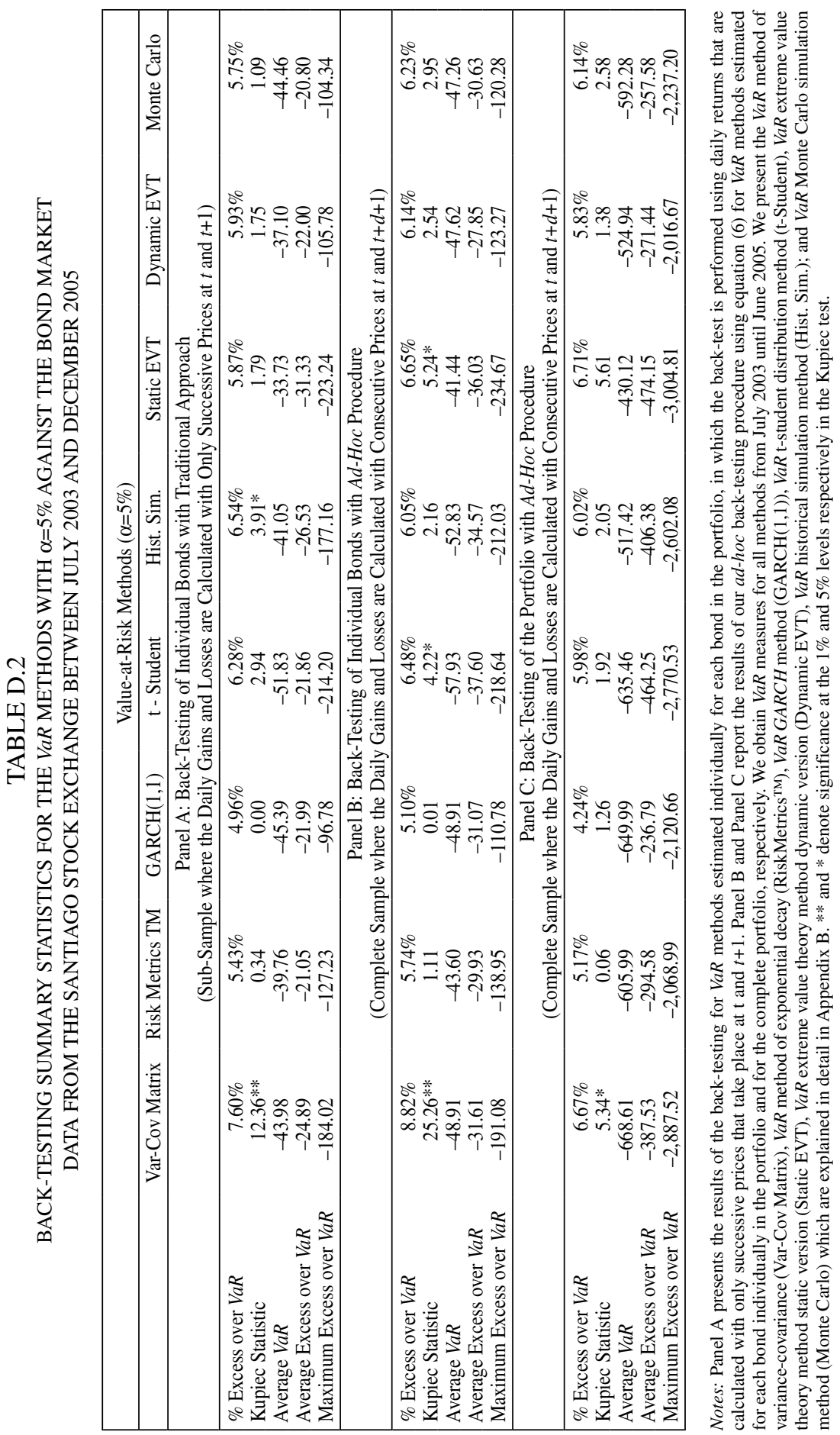




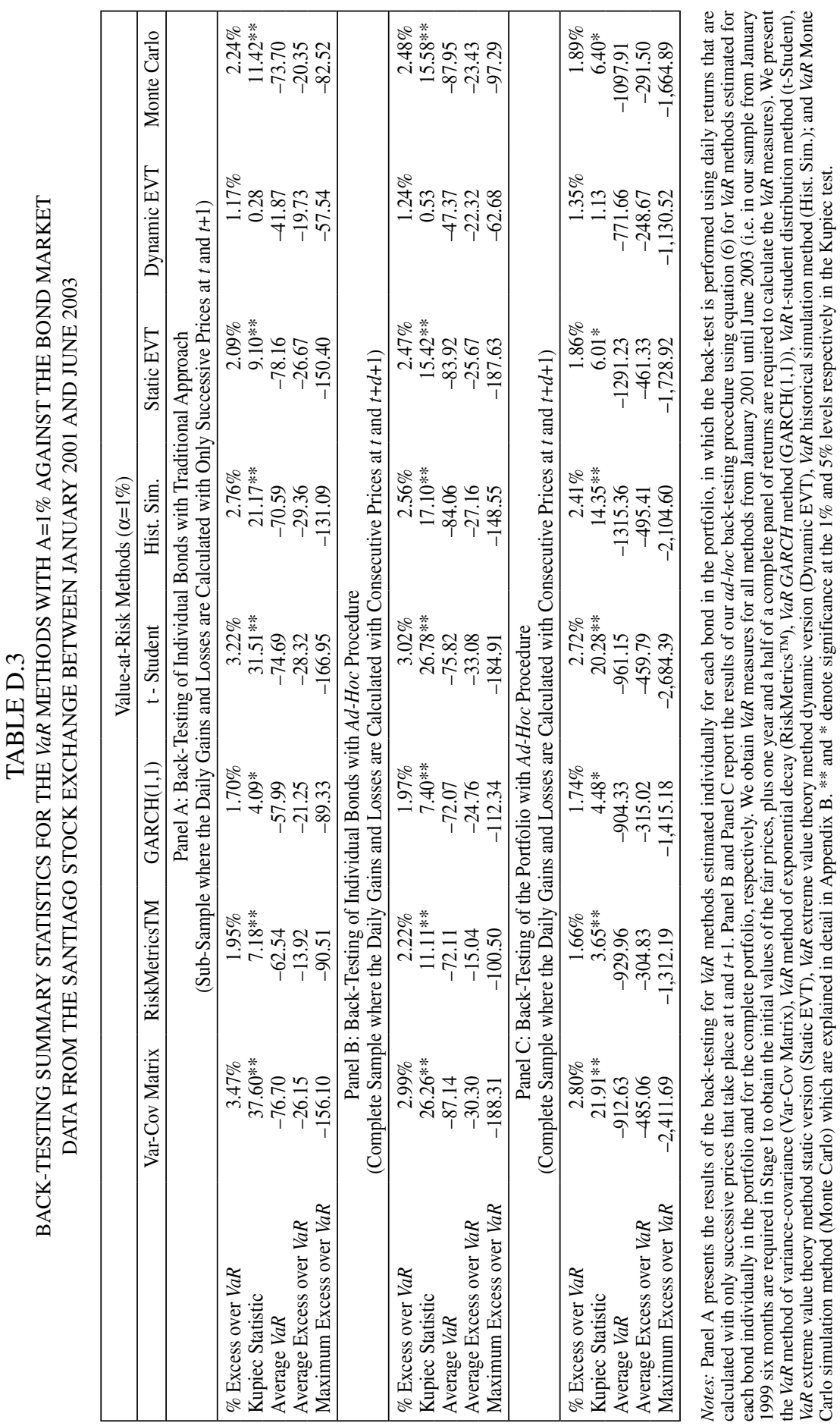




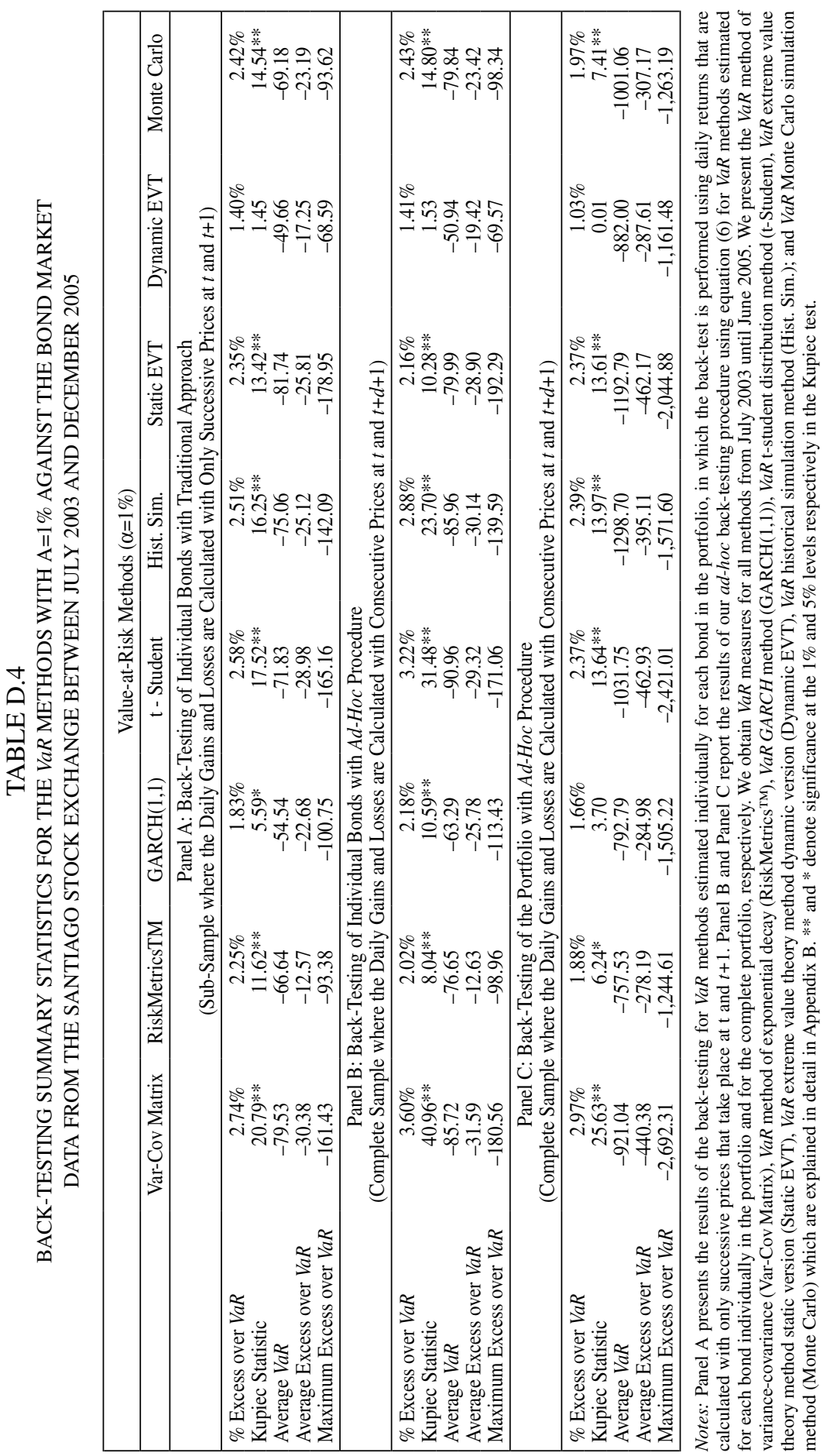

